\title{
Metabolic Turnover of Synaptic Proteins: Kinetics, Interdependencies and Implications for Synaptic Maintenance
}

\author{
Laurie D. Cohen ${ }^{1,2}$, Rina Zuchman ${ }^{3}$, Oksana Sorokina ${ }^{4}$, Anke Müller ${ }^{5,6}$, Daniela C. Dieterich ${ }^{5,6}$, \\ J. Douglas Armstrong ${ }^{4}$, Tamar Ziv ${ }^{3}$, Noam E. Ziv ${ }^{1,2 *}$
}

1 Technion Faculty of Medicine, Lorry Lokey Center for Life Sciences and Engineering, Technion, Haifa, Israel, 2 Network Biology Research Laboratories, Lorry Lokey Center for Life Sciences and Engineering, Technion, Haifa, Israel, $\mathbf{3}$ Smoler Proteomics Center, Faculty of Biology, Technion, Haifa, Israel, $\mathbf{4}$ Institute for Adaptive and Neural Computation, University of Edinburgh, Edinburgh, United Kingdom, $\mathbf{5}$ Leibniz-Institute for Neurobiology, Magdeburg, Germany, $\mathbf{6}$ Institute for Pharmacology and Toxicology, Otto-von-Guericke University, Magdeburg, Germany

\begin{abstract}
Chemical synapses contain multitudes of proteins, which in common with all proteins, have finite lifetimes and therefore need to be continuously replaced. Given the huge numbers of synaptic connections typical neurons form, the demand to maintain the protein contents of these connections might be expected to place considerable metabolic demands on each neuron. Moreover, synaptic proteostasis might differ according to distance from global protein synthesis sites, the availability of distributed protein synthesis facilities, trafficking rates and synaptic protein dynamics. To date, the turnover kinetics of synaptic proteins have not been studied or analyzed systematically, and thus metabolic demands or the aforementioned relationships remain largely unknown. In the current study we used dynamic Stable Isotope Labeling with Amino acids in Cell culture (SILAC), mass spectrometry (MS), Fluorescent Non-Canonical Amino acid Tagging (FUNCAT), quantitative immunohistochemistry and bioinformatics to systematically measure the metabolic half-lives of hundreds of synaptic proteins, examine how these depend on their pre/postsynaptic affiliation or their association with particular molecular complexes, and assess the metabolic load of synaptic proteostasis. We found that nearly all synaptic proteins identified here exhibited half-lifetimes in the range of 2-5 days. Unexpectedly, metabolic turnover rates were not significantly different for presynaptic and postsynaptic proteins, or for proteins for which mRNAs are consistently found in dendrites. Some functionally or structurally related proteins exhibited very similar turnover rates, indicating that their biogenesis and degradation might be coupled, a possibility further supported by bioinformatics-based analyses. The relatively low turnover rates measured here $(\sim 0.7 \%$ of synaptic protein content per hour $)$ are in good agreement with imaging-based studies of synaptic protein trafficking, yet indicate that the metabolic load synaptic protein turnover places on individual neurons is very substantial.
\end{abstract}

Citation: Cohen LD, Zuchman R, Sorokina O, Müller A, Dieterich DC, et al. (2013) Metabolic Turnover of Synaptic Proteins: Kinetics, Interdependencies and Implications for Synaptic Maintenance. PLoS ONE 8(5): e63191. doi:10.1371/journal.pone.0063191

Editor: Mohammed Akaaboune, University of Michigan, United States of America

Received March 5, 2013; Accepted March 29, 2013; Published May 2, 2013

Copyright: (C) 2013 Cohen et al. This is an open-access article distributed under the terms of the Creative Commons Attribution License, which permits unrestricted use, distribution, and reproduction in any medium, provided the original author and source are credited.

Funding: This work has received funding from the United States Israel Binational Science Foundation (2007425), the European Union Seventh Framework Programme under grant agreement nos. HEALTH-F2-2009-241498 ("EUROSPIN"), and the Deutsch-Israelische-Projektkooperation German-Israeli Project Cooperation foundation. The funders had no role in study design, data collection and analysis, decision to publish, or preparation of the manuscript.

Competing Interests: The authors have declared that no competing interests exist.

* E-mail: noamz@netvision.net.il

\section{Introduction}

Chemical synapses contain multitudes of proteins, some of which play direct roles in synaptic transmission, whereas others regulate synaptic function or serve as structural scaffolds. Proteins, including synaptic ones, have finite lifetimes and therefore, need to be continuously replaced with freshly synthesized copies. Given the huge numbers of synaptic connections each central nervous system neuron makes, maintenance of synaptic contents would conceivably place enormous metabolic demands on individual neurons. These demands in turn, depend on anabolic and catabolic rates of synaptic proteins. Surprisingly, perhaps, the turnover kinetics of synaptic proteins have not yet been studied systematically. As a result, the estimates for such kinetics vary widely. Whereas older studies based on radiolabeling methods indicated that the half-lives of some presynaptic proteins can be remarkably long (e.g. [1,2]), more recent in vitro studies have reported half-lives of synaptic proteins in the range of several hours (e.g. [3,4]). Thus, the metabolic cost of maintaining synapses remains largely unknown.

The elaborate, anisotropic architecture of neurons poses unique challenges in terms of synaptic proteostasis: First, synapses, and in particular presynaptic compartments, are often located at enormous distances from the major site of protein synthesis, namely the neuronal cell body. Given the enormous lengths axons can attain, it might be expected that the life-spans of presynaptic proteins would generally be longer than those belonging to somatodendritic compartments. Neurons, however, contain sophisticated and quite efficient transport mechanisms for delivering particular proteins to the far reaches of axons. Yet the transport rates of other synaptic proteins can be rather slow - on the order of a few millimeters per day [5-8]. In addition, substantial evidence has accumulated for 
local synthesis of synaptic proteins in dendrites (reviewed in [912]) and possibly in axons $[13,14]$. Therefore, relationships between turnover rates of particular synaptic proteins and their cellular localization are currently unknown. Moreover, despite much evidence for local protein synthesis in dendrites and axons, it is generally thought that most synaptic proteins, and in particular presynaptic proteins, are transported from the cell body (e.g. [15]; but see [16]). It thus remains unclear how the short lifetimes reported for some synaptic proteins (e.g. [3,4]) are compatible with the relatively long times required for trafficking them to their remote destinations (reviewed in [16]).

Beyond continual replenishment, protein synthesis is believed to play essential roles in driving long-term changes in synaptic composition and function. Moreover, local synthesis and degradation processes have been suggested to affect the properties of specific synapses by changing the abundance of particular synaptic molecules in a spatially confined manner (reviewed in [12,17]). On the other hand, numerous live imaging studies suggest that synaptic molecules - receptors, scaffolding, cytoskeletal and signaling molecules alike - continuously move in, out and between synapses at fairly rapid rates (reviewed in [18-24]). Such continuous interchange would seem to defeat the purported specificity of local synthesis, unless metabolic turnover rates are roughly equivalent to such interchange rates. At present, however, as metabolic turnover rates of synaptic proteins have not been systematically studied, resolving functional relationships between synaptic protein interchange, protein synthesis and synaptic plasticity in a manner that is constrained by physiological evidence is not possible.

In the current study we set out to systematically measure and analyze the metabolic half-lives of synaptic proteins, assess the metabolic load imposed on neurons by the need to continuously synthesize synaptic proteins, examine potential relationships between synaptic protein turnover rates, cellular localization and association with particular molecular complexes, and compare the metabolic turnover rates of specific synaptic proteins with the exchange rates of those molecules. The findings and their implications are described next.

\section{Results}

\section{Metabolic Turnover Rates of Synaptic Proteins Measured by Dynamic SILAC and MS}

To measure metabolic turnover rates of synaptic proteins we used dynamic SILAC (Stable Isotope Labeling with Amino acids in Cell culture) and mass spectrometry (MS) [25-31]. This approach is based on the replacement of select amino acids (AAs) in growth media with similar AAs containing non-radioactive heavy isotopes of particular atoms. With time, these labeled ("heavy") AAs are incorporated into newly synthesized proteins, whereas the degradation of preexisting proteins is associated with the gradual loss of proteins containing "light" (i.e. unlabeled) versions of these AAs. At particular time points, cells are lysed, and protein extracts are digested into short peptides, which are thereafter subjected to MS analysis. For each peptide analyzed and identified, a ratio of heavy to light peptide abundance is calculated, providing a fractional measure of newly synthesized copies for that particular protein species. By repeating this process at several time points, metabolic turnover rates for thousands of proteins can be measured (e.g. [32]).

All experiments were carried out in rat cortical neurons, raised in culture for two weeks. Typically, dynamic SILAC experiments require abrupt and complete media exchanges to assure a full substitution of light AAs with their heavy counterparts. In neuronal cell cultures, during the stage at which most synaptogenesis has been completed (2-3 weeks in culture), aggressive washes and complete media exchanges are severely detrimental to neuronal viability. Therefore, rather than replace media, we added an excess of heavy lysine and arginine. Specifically, after 14 days in culture, heavy lysine and arginine were added to the media, resulting in final concentrations of $\sim 1.9$ and $\sim 2.9 \mathrm{mM}$, respectively, and final heavy to light $(\mathrm{H} / \mathrm{L})$ ratios of $\sim 5: 1$ for both lysine and arginine. $0,1,3$, or 7 days later, the neurons were lysed and extracted; the extracts were separated on polyacrylamide gels, which were subsequently cut into 9 sets of bands according to molecular weight. Each gel slice was then subjected to MS analysis, and an $\mathrm{H} / \mathrm{L}$ ratio for each identified peptide was determined. $\mathrm{H} / \mathrm{L}$ ratios for all peptides belonging to a particular protein species were pooled, providing an average $\mathrm{H} / \mathrm{L}$ ratio for each protein. The entire process is illustrated in Fig. 1.

The procedure described above involved exposure to elevated levels of lysine and arginine. 6x lysine and arginine (heavy or light) concentrations, however, did not noticeably affect neuronal viability, nor did they reduce synaptic densities as assayed by immunolabeling against the postsynaptic density protein PSD-95 (data not shown). Furthermore, profiles of MS-based protein identifications were nearly identical to those obtained in control preparations (Fig. S1). Finally, no effects on spontaneous activity levels were observed when network activity was quantified by multielectrode array recordings after the addition of heavy lysine and arginine as described above (Fig. S2). Collectively these data indicate that elevated lysine and arginine concentrations did not significantly affect viability, activity or neuronal properties.

Altogether 6 separate experiments were performed (two full, four time point experiments and four single time point experiments). Data were pooled as described in Materials and Methods and subsequently analyzed under the following assumptions: 1) the total amount $(\mathrm{H}+\mathrm{L})$ of each protein species was constant over time (but see below), and therefore, incorporation rates of heavy AAs, which reflect protein synthesis, are balanced by the loss rates of light AAs, which reflect protein degradation; 2) heavy AA incorporation and light AA loss are expected to follow single exponential kinetics; 3) the maximal $\mathrm{H} / \mathrm{L}$ ratio expected is the $\mathrm{H} /$ $\mathrm{L}$ ratio for lysine and arginine in the growth medium (5:1, in these experiments). $\mathrm{H} / \mathrm{L}$ ratios for all time points were converted into fractional incorporation ratios ranging from 0 (no incorporation of heavy AAs) to 1.0 (full replacement of light AAs with heavy AAs), after correcting to the maximal possible ratio $(\sim 0.828$; third assumption mentioned above). The corrected fractional ratios at all four time points were fit to single exponential curves and finally, the resulting time constants of these fits were converted to the more commonly used half-life $\left(t_{1 / 2}\right)$ measures (see Materials and Methods for further details). This process is exemplified for the synaptic proteins Munc18-1 and CaMKII $\beta-2$ in Fig. 1B,C. Altogether we identified 4,438 proteins. Out of these, data were obtained at 4 time points for 2,859 identified proteins, including tens to hundreds of synaptic proteins (depending on the definition of a synaptic protein). Fits to single exponential curves were good to excellent for $>92 \%$ of identified proteins (Fig. S3). Proteins for which fits were unacceptable $(\sim 2 \%)$ were not examined further, resulting in satisfactory half-life estimates for 2,802 proteins (Fig. 2; Table S1).

The vast majority of identified proteins exhibited relatively slow turnover rates (mean: 5.05 days, median: 4.18 days), with half-lives ranging from 5 hours or less to more than 50 days (Fig. 2A). To evaluate the half-lives of synaptic proteins, we collated a list of 191 proteins that are either synapse-specific, highly enriched in synaptic compartments, or implicated in synaptic function 

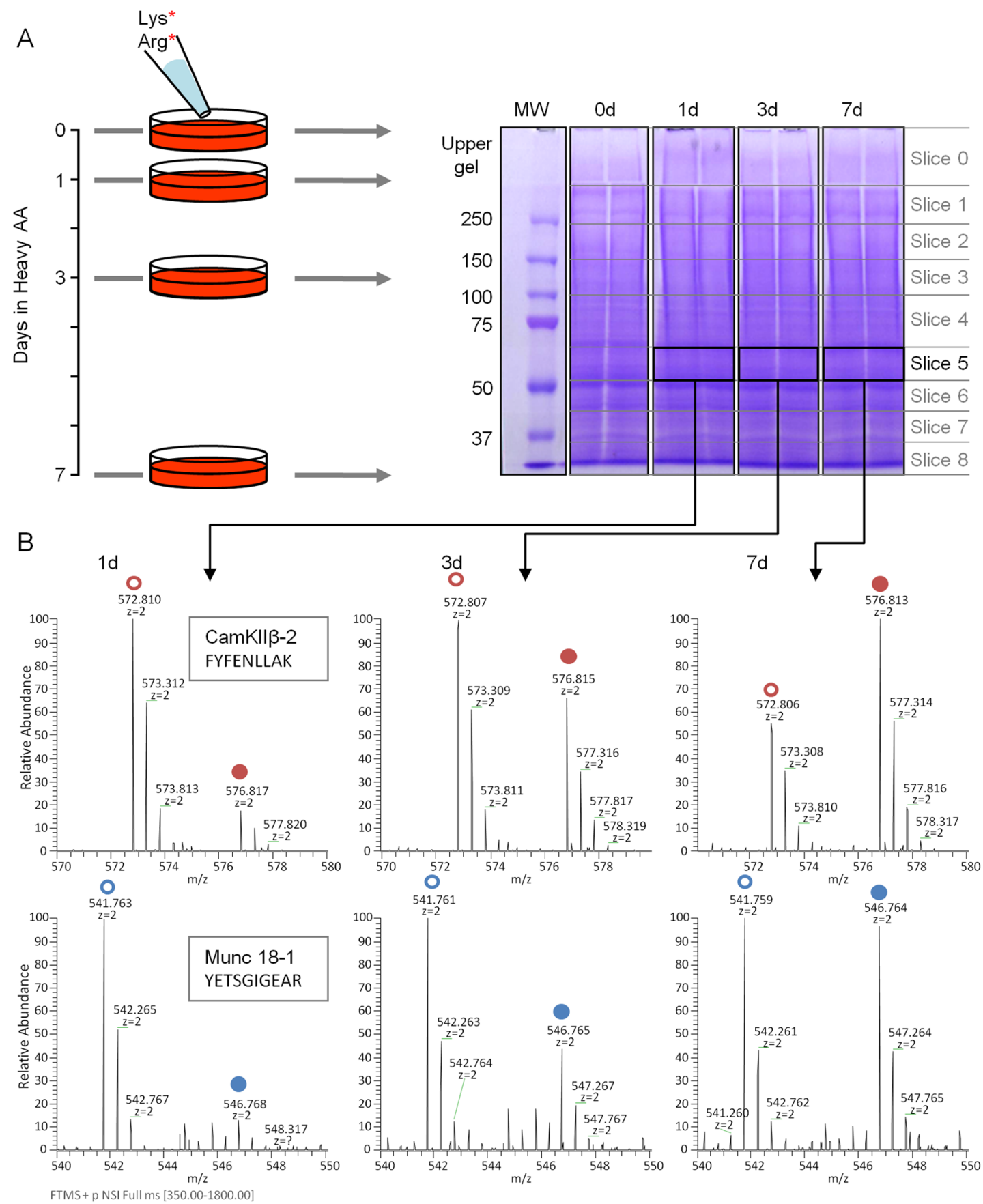

C
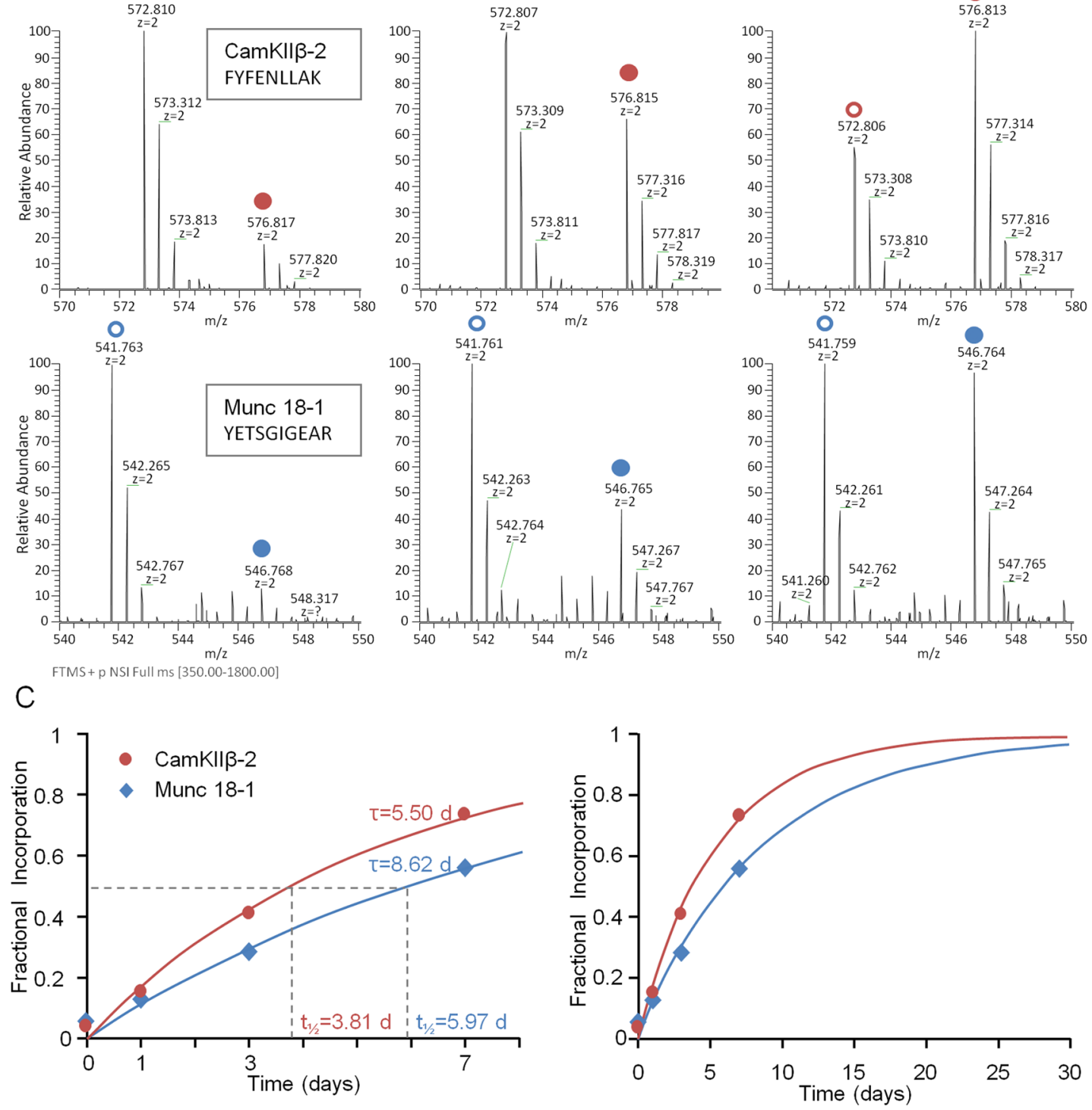
Figure 1. Measuring metabolic protein turnover by SILAC and MS. A) Illustration of the experimental process. At $t=0$, heavy lysine and arginine were added to the media of cortical neurons in primary culture (14 days in vitro). 0, 1, 3 and 7 days afterward, cells were harvested and separated side by side by SDS-PAGE. One such gel (stained with Coomassie Blue) is shown on right. Two lanes were run for each time-point to increase protein amounts. Gels were then cut into 9 slices as indicated, proteins in each slice were digested, and the resulting peptides from each slice and each time point were submitted separately to MS analysis. B) MS spectrogram showing the relative amounts, at three time points, of light (open circles) and heavy (closed circles) populations of two particular peptides from slice 5. C) Heavy AA incorporation rates for two particular proteins (Munc18-1 and CaMKII- $\beta 2$ ). Each data point represents the fractional incorporation values averaged for all peptides belonging to these particular proteins at a given time point. All four data points were used for fitting to exponential curves (solid lines), providing estimates of time constants $(\tau)$ and half-lives as indicated. Graph on right hand side shows extrapolation of same exponential curves to longer times.

doi:10.1371/journal.pone.0063191.g001

(synaptic vesicle proteins, proteins involved in synaptic vesicle recycling, active zone proteins, neurotransmitter receptors, postsynaptic scaffolding molecules, adhesion molecules implicated in synaptic organization, and others; Table 1). As shown in Fig. 2B, these were also quite broadly distributed, although to a somewhat lesser extent. Here too, relatively slow turnover rates were observed (mean: 4.14 days, median: 3.67 days) ranging from 17 hours (TrkB) to 23 days (Agrin). Examples for select groups of synaptic proteins are shown in Fig. $3 \mathrm{~A}-\mathrm{D}$, and schematically in Fig. 3E. Although the half-life estimates described above were based on data pooled from all experiments, half-life estimates based on single experiments correlated extremely well with each other $(r=0.924$; Fig. S4).

As mentioned above, a key assumption in these experiments was that the total amount $(\mathrm{H}+\mathrm{L})$ of each protein species remained constant and thus, incorporation rates represented the complement of degradation rates. Synapse numbers, however, increase at moderate rates during the one week period used here. To quantify changes in synaptic numbers over these periods, we grew cortical neurons on thin-glass dishes under exactly the same experimental conditions and stained these preparations against the postsynaptic density protein PSD-95 at all four time points. It should be stressed that the cell cultures used here and elsewhere [33-34] are much denser than the sparse cell culture preparations typically used for cellular imaging experiments, for example, and are characterized by a very high density of synaptic connections, that is similar in many respects to the synaptic density observed in intact preparations (Fig. S5A). The synaptic density was quantified at 2 separate $\mathrm{Z}$ sections at all time points, resulting in a temporal profile of synaptic density over time (Fig. S5B). We observed that synaptic density increased by approximately $27 \%$ over one week (two separate experiments, 14 to 17 fields of view per time point per experiment). As exemplified in Figs. S5C,D, this increase in synaptic protein content over time would be expected to result in a slight underestimate of turnover rates. Interestingly, the fractional intensities of synaptic protein peptides within the total peptide mixture analyzed by MS barely changed over this period (Fig. S6).

In primary cultures of rat neurons, the period of two to three weeks in vitro represents the end of the rapid synaptogenesis phase and a transition into more mature states. To determine if turnover rates are slower in more mature preparations, we compared the fractional incorporation ratios for all identified proteins 3 days
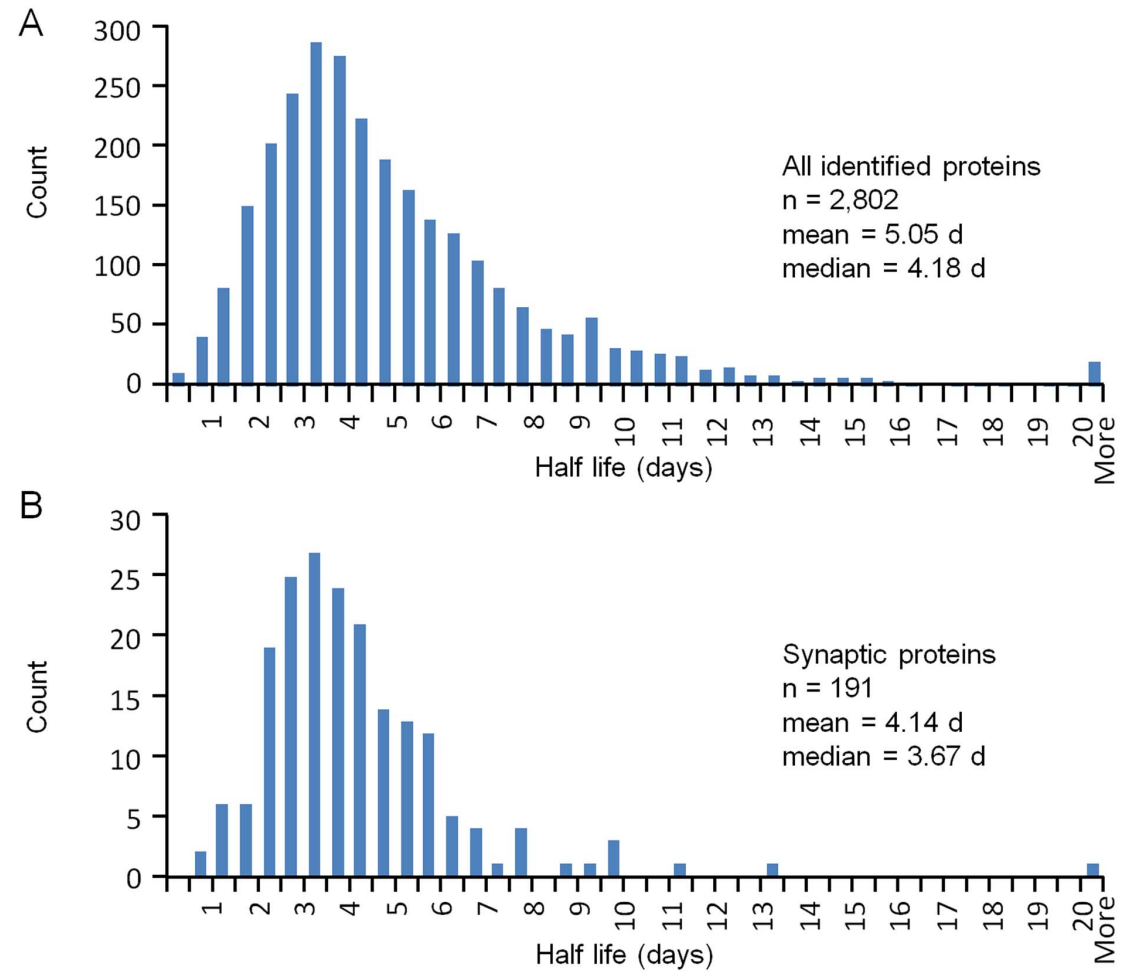

Figure 2. Distributions of metabolic half-life estimates. A) Distribution of metabolic half-life estimates for all identified proteins for which fractional incorporation data was obtained for all four time points. Proteins for which fits to single exponentials were not satisfactory $(\sim 2 \%)$ were excluded. B) Distribution of metabolic half-life estimates for 191 synaptic proteins (Table 1).

doi:10.1371/journal.pone.0063191.g002 
Table 1. Synaptic and synaptically related proteins.

\begin{tabular}{|c|c|c|c|c|c|c|c|c|}
\hline \begin{tabular}{|l} 
Gene \\
Symbol
\end{tabular} & Common name & $\begin{array}{l}\mathbf{t}_{1 / 2} \\
\text { (days) }\end{array}$ & $\begin{array}{l}\text { Gene } \\
\text { Symbol }\end{array}$ & Common name & $\begin{array}{l}t_{1 / 2} \\
\text { (days) }\end{array}$ & $\begin{array}{l}\text { Gene } \\
\text { Symbol }\end{array}$ & Common name & $\begin{array}{l}\mathbf{t}_{1 / 2} \\
\text { (days) }\end{array}$ \\
\hline Ntrk2 & TrkB isoform 1 & 0.72 & Rab4a & Rab-4A & 3.08 & Syn2 & Synapsin II & 4.40 \\
\hline Nedd4 4 & NEDD4 & 0.78 & Cacna $1 b$ & Cav2.2 & 3.09 & Dbnl & Drebrin-like & 4.43 \\
\hline Atxn10 & Ataxin 10 & 1.08 & Rab3gap2 & Rab3 GTPase & 3.10 & Syngr3 & Synaptogyrin 3 & 4.55 \\
\hline Ngef & Ephexin-1 & 1.15 & Fmr1 & FMR1 & 3.11 & Sh3gl2 & Endophilin A1 & 4.59 \\
\hline Cntnap1 & Caspr1/Neurexin-4 & 1.18 & Eef2 & Elongation factor 2 & 3.11 & Mtor & mTOR & 4.61 \\
\hline Unc13a & Munc-13-1 & 1.32 & Dnm1l & Dynamin 1-like & 3.14 & Bcan & Brevican core 1 & 4.63 \\
\hline Ncdn & Norbin & 1.39 & Cadps & CAPS-1 & 3.15 & Actn 4 & Alpha-actinin-4 & 4.67 \\
\hline Nes & Nestin & 1.43 & Arap1 & Centaurin $\delta 2($ ArfGAP 1) & 3.16 & Eef1a1 & Elongation factor 1 -alpha 1 & 4.69 \\
\hline Mpp5 & MAGUK p55 subfamily 5 & 1.51 & Ppfia2 & Liprin $\alpha 2$ & 3.18 & Canx & Calnexin & 4.78 \\
\hline Grin1 & NMDAR1/NR1 & 1.61 & Dclk2 & DCLK2 & 3.19 & Vapa & VAMP-A & 4.79 \\
\hline Grin2b & NMDAR2B/NR2B & 1.80 & Synj1 & Synaptojanin 1 & 3.25 & Homer1 & Homer homolog 1 & 4.82 \\
\hline Ptprs & LAR-PTP2 & 1.91 & Ppfia3 & Liprin $\alpha 3$ & 3.27 & Snap91 & SNAP-91 & 4.86 \\
\hline Epha4 & Eph receptor A4 & 1.95 & Rab8a & Rab-8A & 3.27 & Syn1 & Synapsin I & 4.95 \\
\hline Gria2 & GluA2 & 1.95 & Scamp1 & Scamp1 & 3.29 & Stxbp3 & Syntaxin binding 3 & 4.96 \\
\hline Gria3 & GluA3 & 2.04 & Hip1r & Huntingtin interacting 1 & 3.29 & Ap2a2 & AP- $2 \alpha 2$ & 4.98 \\
\hline Ppp1r9a & Neurabin 1 & 2.08 & Erc1 & ELKS/Erc1/CAST2 & 3.30 & Agap3 & Centaurin $\gamma 3$ (ArfGAP3) & 4.99 \\
\hline Stx6 & Syntaxin 6 & 2.10 & Rab5c & $\operatorname{Rab} 5 c$ & 3.32 & Dlg1 & Dlg1/SAP-97 & 5.01 \\
\hline Dlg3 & Dlg3/SAP-102 & 2.13 & Sv2b & SV2B & 3.36 & Camk2g & CaMKIl $\gamma$ & 5.03 \\
\hline Syne1 & Nesprin 1 & 2.15 & Map2 & MAP2 & 3.36 & Vapb & VAMP-B & 5.10 \\
\hline Fxr2 & Fxr2 & 2.18 & Macf1 & Liprin $\beta 1$ & 3.45 & Ap2a2 & AP- $2 \alpha 2$ & 5.17 \\
\hline Rab3a & Rab 3a & 2.26 & Scfd1 & Syntaxin-binding 1-like & 3.46 & $\mathrm{Cd} 47$ & CD47 & 5.20 \\
\hline Rasa3 & RasGAP3 & 2.27 & Rab5b & Rab $5 b$ & 3.52 & Rptor & Raptor & 5.21 \\
\hline Lphn1 & Latrophilin-1 & 2.29 & Cyfip2 & FMR1 interacting 2 & 3.55 & Syngr1 & Synaptogyrin 1 & 5.22 \\
\hline Cdh2 & $\mathrm{N}$-cadherin & 2.31 & Rph3a & Rabphilin $3 \mathrm{~A}$ & 3.55 & Asap2 & ArfGAP2 & 5.23 \\
\hline Snap25 & SNAP-25 & 2.31 & Napg & NSF attachment $\gamma$ soluble & 3.56 & Lin7c & $\operatorname{lin}-7$ homolog $C$ & 5.29 \\
\hline Camk4 & CaMKIV & 2.37 & Ptpra & PTPRA & 3.59 & $\mathrm{Ap} 2 \mathrm{~m} 1$ & AP- $-2 \mu$ & 5.35 \\
\hline Ppfia4 & Liprin $\alpha 4$ & 2.40 & Cdk5 & CDK5 & 3.59 & Sept3 & Septin 3 & 5.36 \\
\hline Epha5 & Eph receptor A5 & 2.41 & Nsf & NSF & 3.59 & Negr1 & Kilon & 5.38 \\
\hline Kctd12 & KCTD12 & 2.43 & Srcin 1 & SNAP-25 interacting (SNIP) & 3.60 & Stx $1 b$ & Syntaxin $1 B$ & 5.40 \\
\hline Rab3a & Rab-3A & 2.45 & Atp6v0a1 & SV proton pump 116 kDa & 3.63 & Plxnd1 & Plexin-D1 & 5.60 \\
\hline Snap29 & SNAP-29 & 2.45 & Atp6v1a & ATPase, $\mathrm{H}+$ subunit $\mathrm{A}$ & 3.65 & Cacna2d1 & Cacna2d1 & 5.60 \\
\hline Rab11b & Rab 11b & 2.46 & Dlg4 & Dlg4/PSD-95 & 3.67 & Caskin1 & Caskin-1 & 5.66 \\
\hline Napa & SNAP- $\alpha$ & 2.48 & Rab5a & Rab 5a & 3.68 & Ctnna2 & Catenin $\alpha 2$ & 5.71 \\
\hline Camk1d & CaMKI $\delta$ & 2.50 & Naa15 & NMDAR regulated 1 & 3.69 & L1cam & Ncam L1 & 5.73 \\
\hline Pclo & Piccolo & 2.54 & Ap3d1 & AP-3 $\delta 1$ & 3.70 & Ap2a1 & AP-2 $\alpha 1$ & 5.90 \\
\hline Nlgn2 & Neuroligin 2 & 2.56 & $\mathrm{Htt}$ & Huntingtin & 3.75 & Amph & Amphiphysin & 5.93 \\
\hline Bsn & Bassoon & 2.57 & Pacsin 1 & Syndapin 1 & 3.77 & Ap2b1 & AP-2 $\beta$ & 5.95 \\
\hline Git2 & ArfGAP2 GIT2 & 2.57 & Dlg2 & Dlg2/PSD-93 & 3.80 & Stxbp1 & Munc18-1 & 5.98 \\
\hline Nrcam & $\mathrm{NrCAM}$ & 2.58 & Sv2a & $\mathrm{sV} 2 \mathrm{a}$ & 3.80 & Itsn1 & Intersectin 1 & 5.98 \\
\hline Rab7a & Rab 7a & 2.60 & Camk2b & CaMKII $\beta 2$ & 3.81 & $\mathrm{Cttn}$ & Cortactin isoform B & 5.98 \\
\hline Nlgn3 & Neuroligin 3 & 2.61 & Mllt4 & Afadin & 3.82 & Sept5 & Septin 5 & 5.99 \\
\hline Nrxn3 & Neurexin $3 \alpha$ & 2.61 & Stx7 & Syntaxin 7 & 3.83 & Adap1 & Centaurin $\alpha 1$ (ArfGAP1) & 6.01 \\
\hline Rufy3 & Singar 2 & 2.64 & Dnm1l & Dynamin 1-like & 3.83 & Actn1 & Brain-specific $\alpha$ actinin & 6.06 \\
\hline Gabbr1 & GABA-BR1 & 2.70 & Stxbp5 & Tomosyn & 3.91 & Dbn1 & Drebrin & 6.27 \\
\hline Syt1 & Synaptotagmin 1 & 2.74 & Dtnb & Dystrobrevin $\beta$ & 3.96 & Nptn & Neuroplastin & 6.32 \\
\hline Ctnnb1 & Catenin $\beta 1$ & 2.78 & Camkv & CaMKV & 4.02 & Cask & CASK & 6.35 \\
\hline Mpp2 & MAGUK p55 subfamily 2 & 2.78 & Cyfip1 & FMR1 interacting 1 & 4.04 & D10Wsu52e & SynGAP1 homolog & 6.56 \\
\hline Hip1 & Huntingtin-interacting 1 & 2.79 & Sirpa & Sirpa & 4.05 & Vat1 & VAT-1 homolog & 6.60 \\
\hline Syngap1 & SynGAP1 & 2.82 & Akap5 & Akap5 & 4.06 & Adap1 & Centaurin $\alpha$ (ArfGAP1) & 6.93 \\
\hline
\end{tabular}


Table 1. Cont.

\begin{tabular}{|c|c|c|c|c|c|c|c|c|}
\hline $\begin{array}{l}\text { Gene } \\
\text { Symbol }\end{array}$ & Common name & $\begin{array}{l}t_{1 / 2}^{1 / 2} \\
\text { (days) }\end{array}$ & $\begin{array}{l}\text { Gene } \\
\text { Symbol }\end{array}$ & Common name & $\begin{array}{l}t_{1 / 2} \\
\text { (days) }\end{array}$ & $\begin{array}{l}\text { Gene } \\
\text { Symbol }\end{array}$ & Common name & $\begin{array}{l}t_{1 / 2} \\
\text { (days) }\end{array}$ \\
\hline Vamp7 & VAMP-7 & 2.86 & Kcnab2 & Kv- $\beta 2$ & 4.09 & Nfasc & Neurofascin & 6.97 \\
\hline Nrxn1 & Neurexin 1 & 2.89 & Syp & Synaptophysin & 4.09 & Epb4111 & Band 4.1-like & 7.46 \\
\hline Kalrn & Kalirin & 2.91 & Abi1 & Abelson interactor 1 & 4.09 & $\operatorname{Tln} 2$ & Talin 2 isoform 3 & 7.51 \\
\hline $\mathrm{Napb}$ & NSF attachment $\beta$ soluble & 2.92 & Cttnbp2 & Cortactin-binding protein 2 & 4.10 & Ppm1f & CaM kinase phosphatase & 7.61 \\
\hline Syngr2 & Synaptogyrin 2 & 2.92 & Epn1 & Epsin 1 & 4.13 & Sntb1 & Syntrophin $\beta 1$ & 7.62 \\
\hline SIc12a5 & Neuronal K-Cl cotransporter & 2.92 & Arl6ip5 & PRA1 family 3 & 4.14 & Stx4 & Syntaxin $4 \mathrm{~A}$ & 7.91 \\
\hline Hip1r & Huntingtin interacting 1-rltd & 2.95 & Shank2 & Shank2/ProSAP1 & 4.14 & Ncam1 & $\mathrm{N}-\mathrm{Cam} 1$ & 8.80 \\
\hline Acap2 & Centaurin $\beta 2$ (ArfGAP 2) & 2.97 & Sh3gl1 & Endophilin A2 & 4.18 & Palm & Paralemmin-1 & 9.41 \\
\hline Rtn4 & Nogo & 2.97 & Plxna3 & Plexin-A3 & 4.19 & Sept11 & Septin 11 & 9.58 \\
\hline Dnm1 & Dynamin 1 & 3.02 & Dclk1 & DCLK1 & 4.20 & MarcksI1 & MARCKS-related & 9.64 \\
\hline Camk2a & CaMKII $\alpha$ & 3.02 & Camk2d & CaMKIII & 4.21 & Tnr & Tenascin R & 9.99 \\
\hline Tecr & Synaptic glycoprotein SC2 & 3.03 & Syncrip & Synaptotagmin-binding & 4.23 & Sypl1 & Synaptophysin-like 1 & 11.46 \\
\hline Ppp1r9b & Neurabin 2 & 3.04 & Stx16 & Syntaxin 16 & 4.26 & Tnc & Tenascin C & 13.04 \\
\hline Nedd4I & NEDD4-like & 3.06 & Bcan & Brevican core & 4.28 & Agrn & Agrin & 23.59 \\
\hline Rab3c & $\operatorname{Rab} 3 c$ & 3.07 & Dnm2 & Dynamin 2 & 4.36 & & & \\
\hline
\end{tabular}

after exposure to heavy lysine and arginine in neurons exposed to these heavy AAs after two and three weeks in culture. Plotting the fractional incorporation ratios against each other (Fig. S7) revealed no trend, with a regression line exhibiting a slope of 1.006 $(r=0.92)$. Thus, no significant differences in overall protein metabolic turnover rates were observed between neurons maintained in culture for two or three weeks. Taken together, these findings suggest that a breach of the assumption of constant protein content was not a major confounding factor.

Finally, we repeated the dynamic SILAC experiment in a more conventional manner - that is, we grew cortical preparations in arginine and lysine free media to which labeled ("heavy") variants of these AAs were added at nominal concentrations. After two weeks, the preparations were chased with media containing the unlabeled ("light") isotopic forms of these AAs (see Materials and Methods). As before, neurons were lysed and extracted after 0, 1, 3 , or 7 days and the digested extracts were subjected to MS analysis. The half-lives measured in this fashion correlated quite well with the estimates described above $(r=0.85,1100$ proteins identified in both data sets), but were 20-30\% shorter (mean $=4.00$ days; median $=3.42$ days; 1501 proteins; Fig. S8). To exclude the possibility that these differences resulted from preparation to preparation variability, we performed in sister cell culture preparations a single time-point (3 days) SILAC experiment to compare the two protocols used here as well as the effects of media exchanges (washes) alone. Here too we noted that the half-life estimates for synaptic proteins obtained by "conventional" SILAC were slightly shorter $(\sim 20 \%)$. We noted, however, that in "conventional" SILAC experiments, labeling with heavy AAs was not complete even after two weeks (reaching $85 \% \pm 6 \%$ ), requiring some correction to the fractional incorporation values at the beginning of the chase period. Moreover, the washes involved in the chase procedure were also associated with some shortening of the half-life estimates $(5-10 \%)$. Given these complications, we feel the latter estimates were less reliable, and therefore, all further analysis was limited to the data obtained in the experiments described in figures $1,2,3$.

\section{Metabolic Turnover Rates of Synaptic Proteins Measured by FUNCAT and Quantitative Immunohistochemistry}

The relatively slow turnover rates of synaptic proteins might seem surprising, given prior studies reporting synaptic proteins half-lives on the order of 4-20 hours in similar preparations [3]. It remained possible, however, that metabolic turnover rates reported here for whole cell extracts differ from metabolic turnover rates of synaptic proteins confined to synapses. We thus probed protein turnover rates at synapses using two different approaches.

In the first, we employed FUNCAT (FlUorescent NonCanonical Amino acid Tagging [35]) to visualize newly synthesized proteins and assess their degradation rates with a special focus on labeled proteins at synaptic compartments. A $24 \mathrm{~h}$ pulse with the non-canonical amino acid azidohomoalanine (AHA) allowed robust labeling of newly synthesized proteins in primary cultures of rat hippocampal neurons and subsequent visualization with a fluorescent Tetramethylrhodamine (TAMRA) tag using "click chemistry". Abundant AHA-bearing proteins were detected within dendrites as well as in Synaptophysin positive synapses after a $24 \mathrm{~h}$ pulse (Fig. 4A). To measure global degradation rates of these newly synthesized proteins, preparations were chased for $24 \mathrm{~h}$ and $48 \mathrm{~h}$ with high concentrations of the natural amino acid methionine $(4 \mathrm{mM})$ to stop the incorporation of AHA into nascent proteins [35]. We found that the fluorescence of pulse-labeled AHA-bearing proteins in synapses was reduced to $70 \%$ and $55 \%$ after 24 and $48 \mathrm{~h}$ respectively, as compared to samples fixed directly after $24 \mathrm{~h}$ pulse labeling (Fig. 4B).

In a second approach, we exposed neurons maintained in culture for 14 days to the protein synthesis inhibitor anisomycin $(25 \mu \mathrm{M})$ for 10 hours and used quantitative immunofluorescence directed against 9 synaptic proteins (Bassoon, Piccolo, Rim, Synapsin-I, VGAT, SV2A, PSD-95, ProSAP1/Shank2, Pro- 

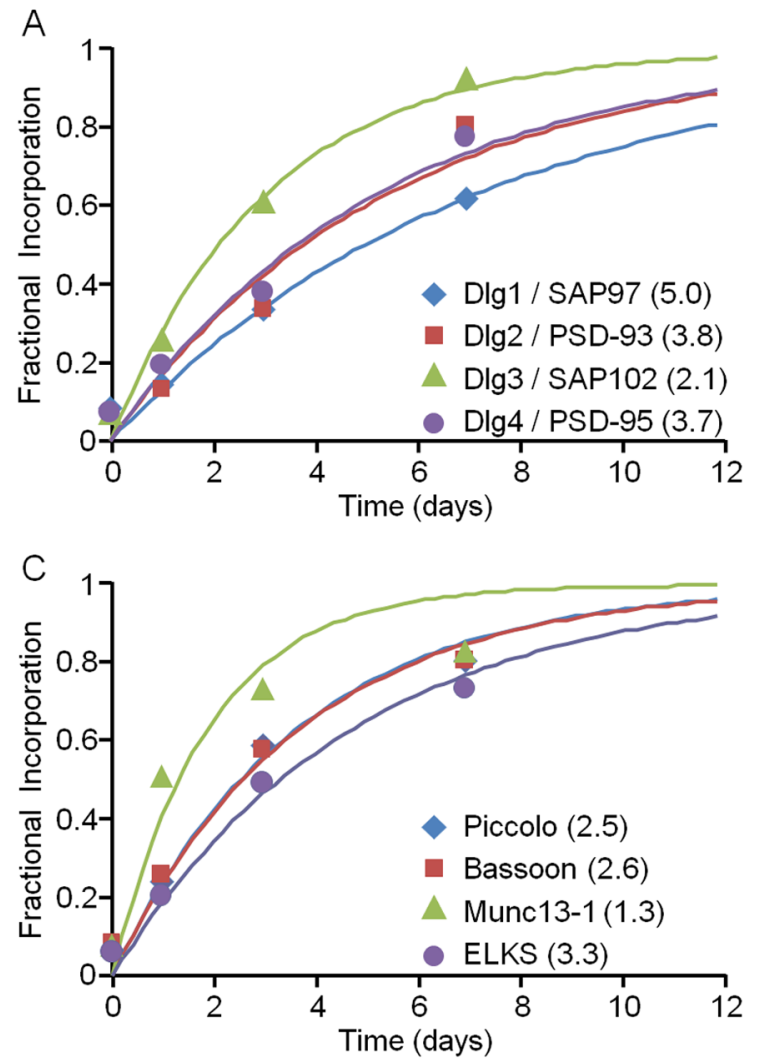

$E$

T $\quad t_{1 / 2}$ (days) (days)

Postsynaptic

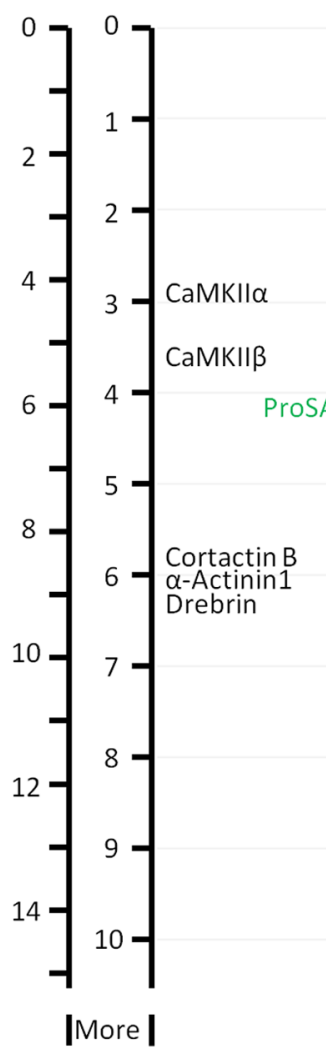

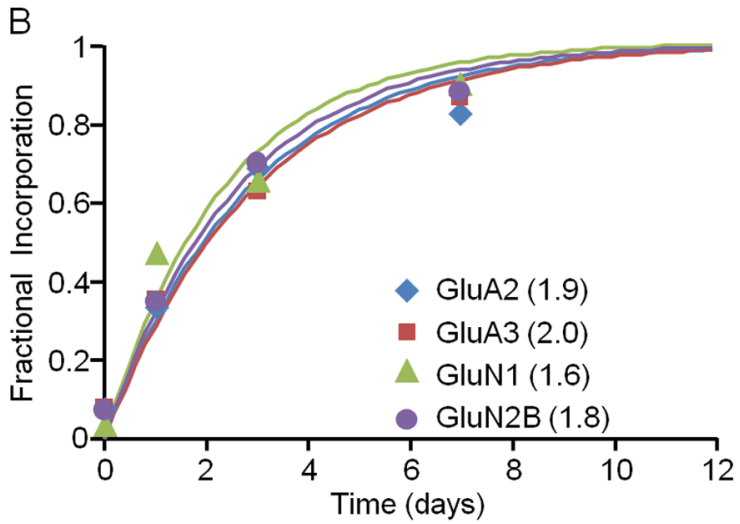

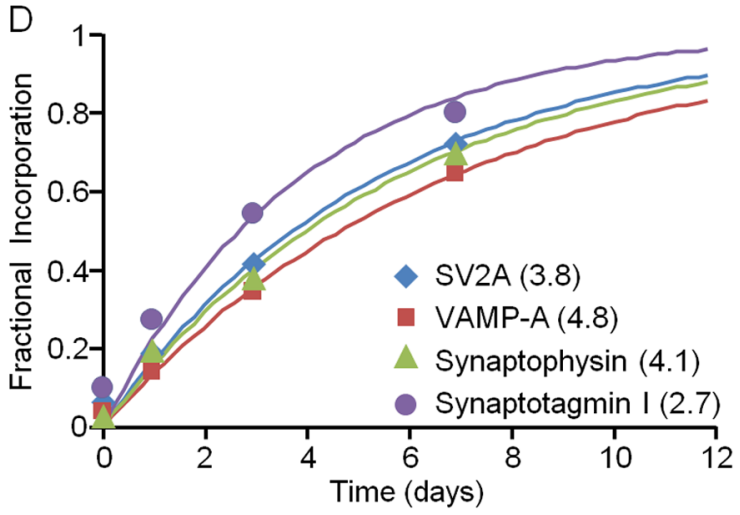

Presynaptic

$\mathbf{t}_{1 / 2}$ (days)

TrkB

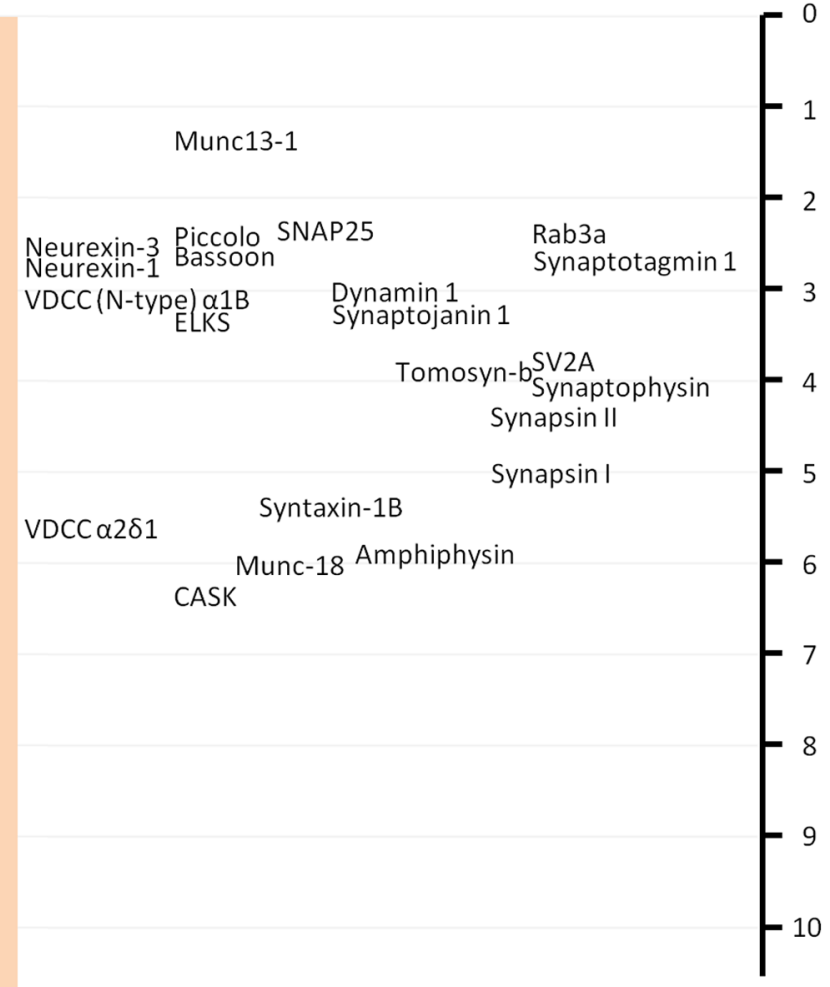

Agrin 
Figure 3. Metabolic half-life estimates for well characterized synaptic proteins. A-D) Heavy AA incorporation rates for four groups of synaptic proteins: Glutamatergic synapse Dlg family of scaffolding molecules (A); glutamate receptor subunits (B); cytoskeleton of the active zone (CAZ) molecules (C); and synaptic vesicle molecules (D). Each data point (as in Fig. 1C) represents heavy AA fractional incorporation values averaged for all peptides belonging to that particular protein at a given time point. The solid lines represent best fits to single exponential curves. Half-life estimates (in days) based on these fits are provided in the legend (brackets). E) Metabolic half-life estimates for a select group of synaptic proteins. Proteins associated primarily with glutamatergic and GABAergic synapses are shown in green and red respectively. Note that proteins with very similar half-lives were sometimes separated slightly to increase readability.

doi:10.1371/journal.pone.0063191.g003

SAP2/Shank3) to compare immunofluorescence levels in these preparations to those observed in matched preparations exposed only to carrier solution for the same time period. We found that synaptic immunofluorescence levels were only slightly reduced following 10 hours of exposure to anisomycin (Fig. 5A-I). In fact, plotting immunofluorescence levels of anisomycin treated neurons against control values for all 9 proteins indicated a general loss of $<10 \%$ over this 10 hour period (Fig. 5J). Reductions in somatic immunofluorescence were similarly modest (data not shown). As a positive control we verified that anisomycin suppressed the expression of nuclear c-fos following exposure to low levels of glutamate (data not shown). These experiments are thus in good agreement with our SILAC analysis and further indicate that the metabolic half-lives of synaptic proteins are typically on the order of several days.

\section{Metabolic Turnover Rates, Cellular Compartmentalization and Functional Relationships}

A comparison of metabolic turnover rates measured for synaptic proteins to those of the entire population of identified proteins indicates that the mean half-life measured for synaptic proteins is shorter than that measured for the entire population $(4.17 \pm 0.17$ vs. 5.06 \pm 0.07 , mean \pm SEM, synaptic and entire population, respectively, $\mathrm{p}<10^{-3}$, Kolmogorov-Smirnov test). Comparison of half-life distributions (Fig. 2) indicates that the difference is mainly due to a long tail of proteins with slow turnover rates found in the general population. Gene Ontology (GO) based analysis per- formed using "Perseus" (http://www.maxquant.org/) and "GORILLA" (Gene Ontology enRIchment anaLysis and visuaLizAtion tool [36]), indicated that this long tail of relatively stable proteins is highly enriched in mitochondrial and extracellular matrix proteins (Figs. S9, S10A). Conversely, GO analysis indicated enrichment of Golgi apparatus-related proteins in the list of proteins with short half-lives, and to a lesser degree, protein degradation systems and dendritic shaft proteins (Fig. S10B).

The unique architecture of neurons might be expected to impose constraints on protein turnover rates that differ from one neuronal compartment to another. For example, proteins of axonal presynaptic compartments, which are typically located at large distances from the biosynthetic machinery at the cell body, might be expected to undergo slower turnover than, for instance, postsynaptic proteins synthesized locally in dendrites. To examine this possibility we collated groups of well characterized proteins (Fig. 6): 1) presynaptic vesicle proteins [37]; 2) presynaptic active zone molecules [38,39]; 3) postsynaptic density (PSD) proteins of glutamatergic synapses [40]; and 4) proteins for which dendritically located mRNAs are consistently found [41-51] (reviewed in [52-54]). We then determined whether metabolic turnover rates differed significantly among these groups. As shown in Fig. 6 the differences were surprisingly modest. Perhaps most unexpected was the finding that the half-lives of presynaptic active zone molecules (Piccolo, Bassoon, Munc13-1, ELKS, $\alpha$-Liprins) and synaptic vesicle proteins (with and without transmembrane domains) were not significantly longer (if anything, they were
A
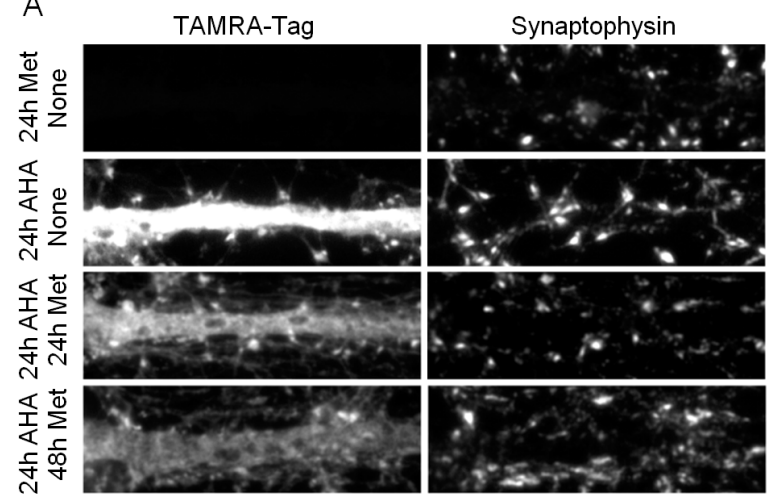

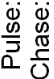

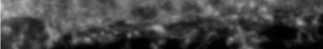

MAP2 / TAMRA-Tag / Sph
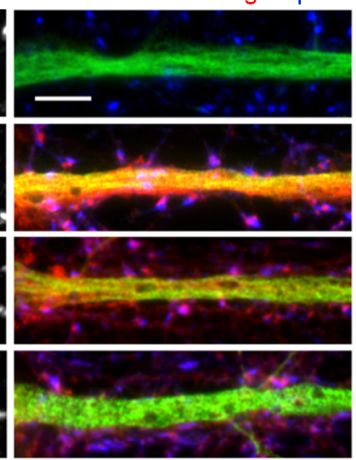

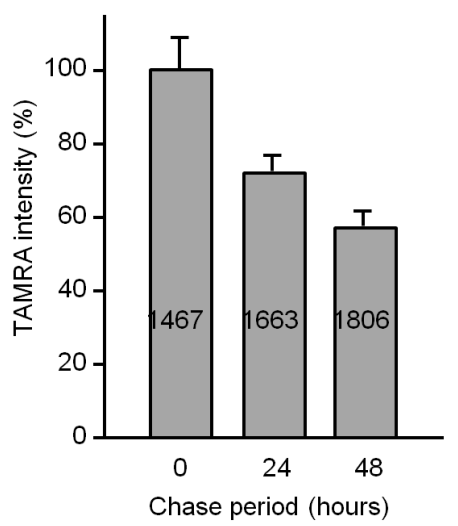

Figure 4. Degradation rates of newly synthesized proteins measured in dendritic spines. A 24 h pulse with 4 mM AHA was used to label newly synthesized proteins. Cells were subsequently fixed - immediately or after 24 or $48 \mathrm{~h}$ chase periods with high concentrations of methionine. Newly synthesized proteins (proteins containing AHA) were then visualized with a TAMRA-TAG using FUNCAT. A) Examples of proximal dendritic segments after visualization of newly synthesized proteins by FUNCAT, and after immunostaining against MAP2 and Synaptophysin (Sph). Note the strong TAMRA fluorescence in dendrites as well as in Synaptophysin positive synapses, and the reduction in TAMRA fluorescence after 24 and $48 \mathrm{~h}$ chase periods. Note also that no TAMRA fluorescence is observed in neurons that were not exposed to the AHA pulse (top row). Color coding: MAP2 green, TAMRA-tag - magenta/red, Sph - blue. Scale bar: $5 \mu \mathrm{m}$. B) Quantification of TAMRA fluorescence intensity in synaptophysin-positive synapses following increasingly longer chase periods. Data is shown as average \pm SEM. Data obtained from two independent experiments (two to three coverslips per experiment) and a total number of $40-46$ proximal dendrites. The number of spines for which TAMRA-intensity was quantified is indicated inside the bars.

doi:10.1371/journal.pone.0063191.g004 

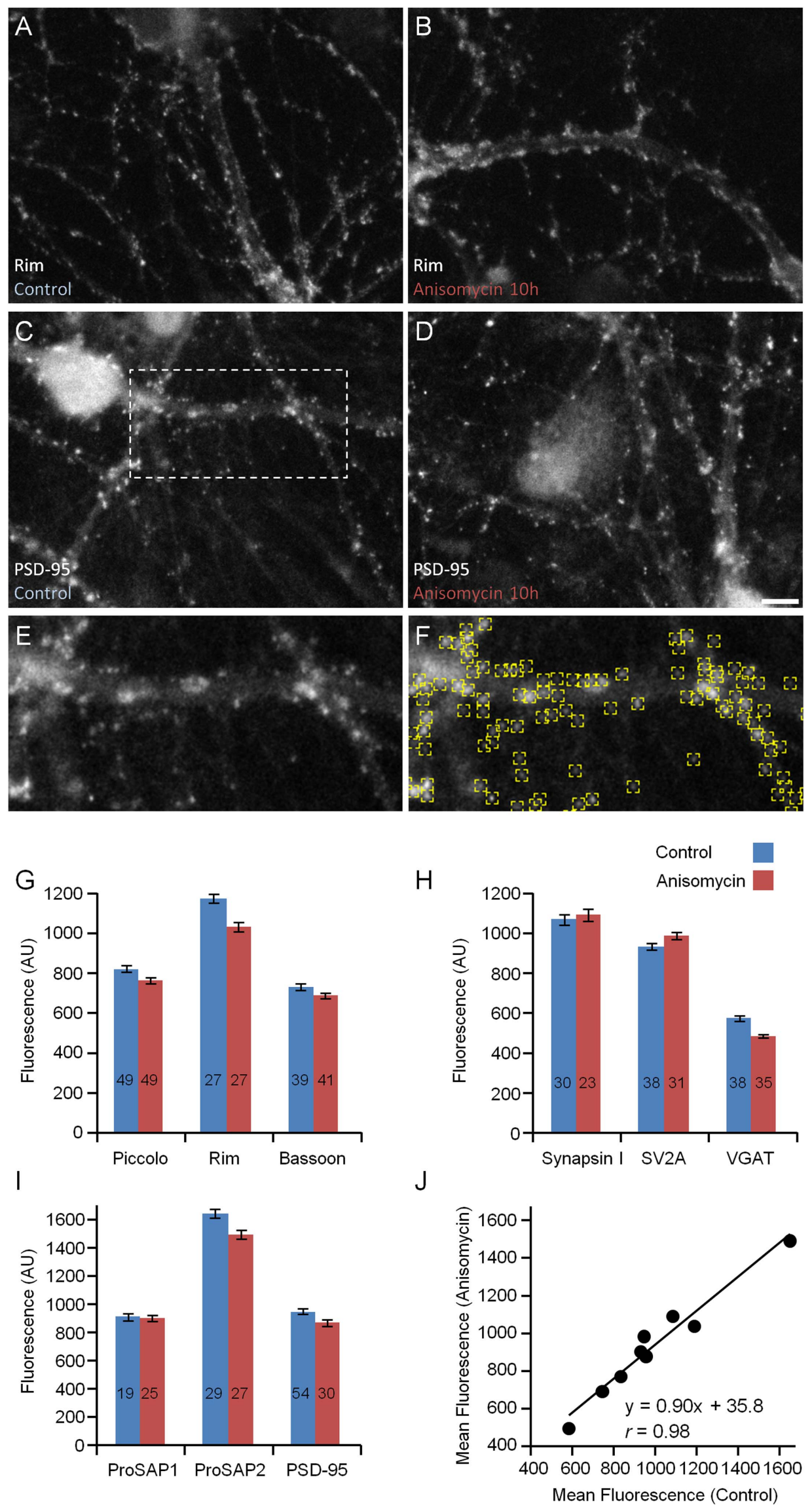
Figure 5. Minor loss of synaptic proteins from synaptic sites following suppression of protein synthesis for 10 hours. Quantitative immunocytochemistry of neurons exposed to the protein synthesis blocker anisomycin $(25 \mu \mathrm{M})$ for 10 hours and thereafter labeled against nine different synaptic proteins. Neurons labeled against the CAZ protein Rim after exposure to carrier solution (A) or anisomycin (B). Neurons labeled against the PSD protein PSD-95 after exposure to carrier solution (C) or anisomycin (D). Scale bar, $10 \mu \mathrm{m}$. E) Enlarged view of region enclosed in the rectangle in C illustrating a programmatic localization of fluorescent puncta (F). Note that puncta are detected correctly regardless of their brightness. G-I) Changes in synaptic immuofluorescence levels measured following exposure to anisomycin for 10 hours (average \pm SEM). Numbers within bars indicate the number of fields of view analyzed for each data set. Each field of view contained $\sim 297 \pm 122$ puncta (average \pm standard deviation). J) Average immuofluorescence levels following anisomycin treatment plotted against immunofluorescence levels in untreated neurons (same data as in panels G-I).

doi:10.1371/journal.pone.0063191.g005

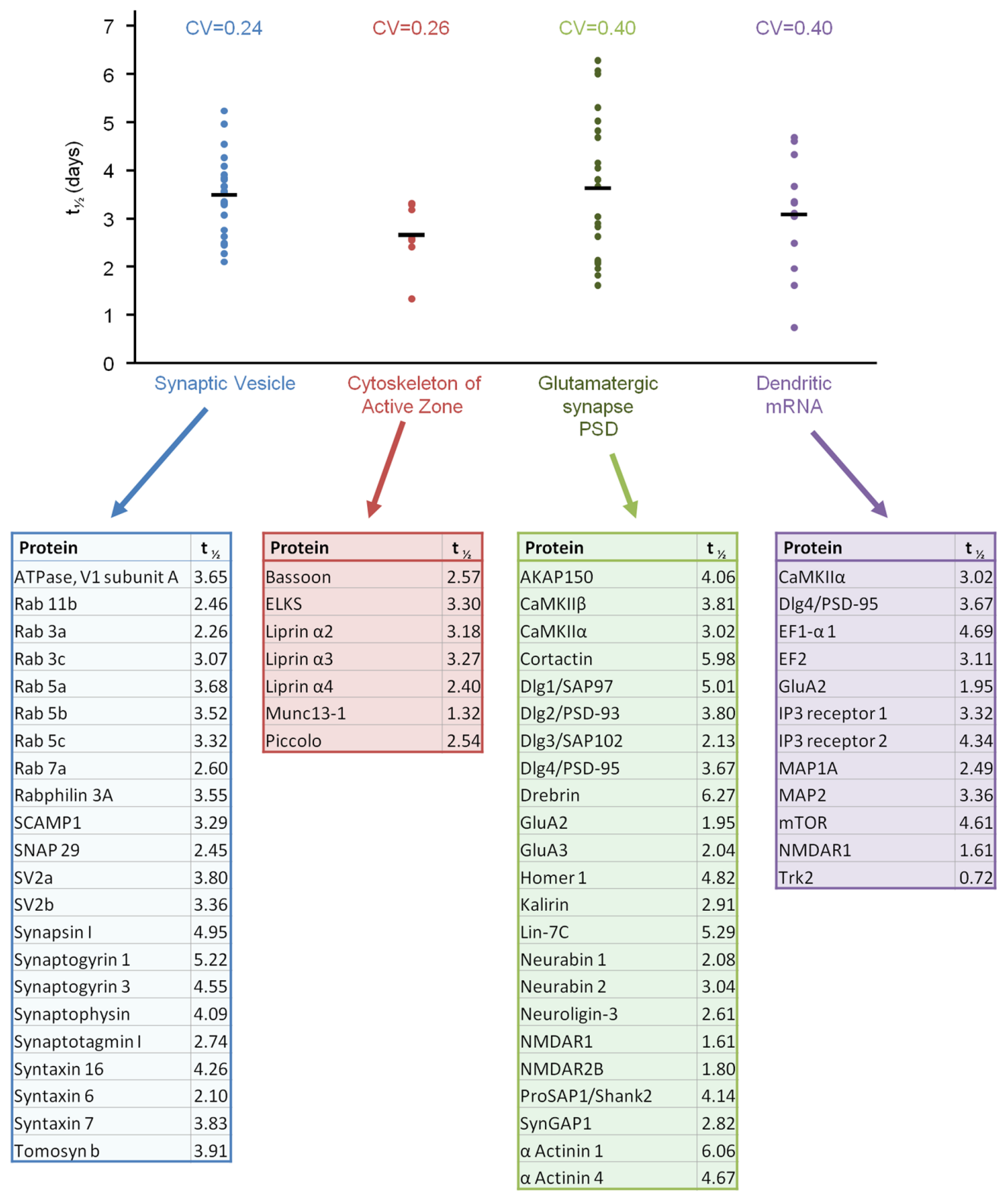

Figure 6. Comparisons of metabolic half-life estimates for proteins localized to particular synaptic compartments. Groups of well characterized proteins were curated manually and estimates of their metabolic half-lives were compared. Each dot represents the half-life value of one protein. Horizontal bars represent average values for each group. The coefficient of variation for each group is provided above each group. Proteins contained in each group along with estimates of their metabolic half-lives are listed below the graph. Except for the difference between the Synaptic Vesicle and Cytoskeleton of Active Zone groups $(p=0.01)$ all other differences between groups were not statistically significant (Kolmogorov-Smirnov test).

doi:10.1371/journal.pone.0063191.g006 
A

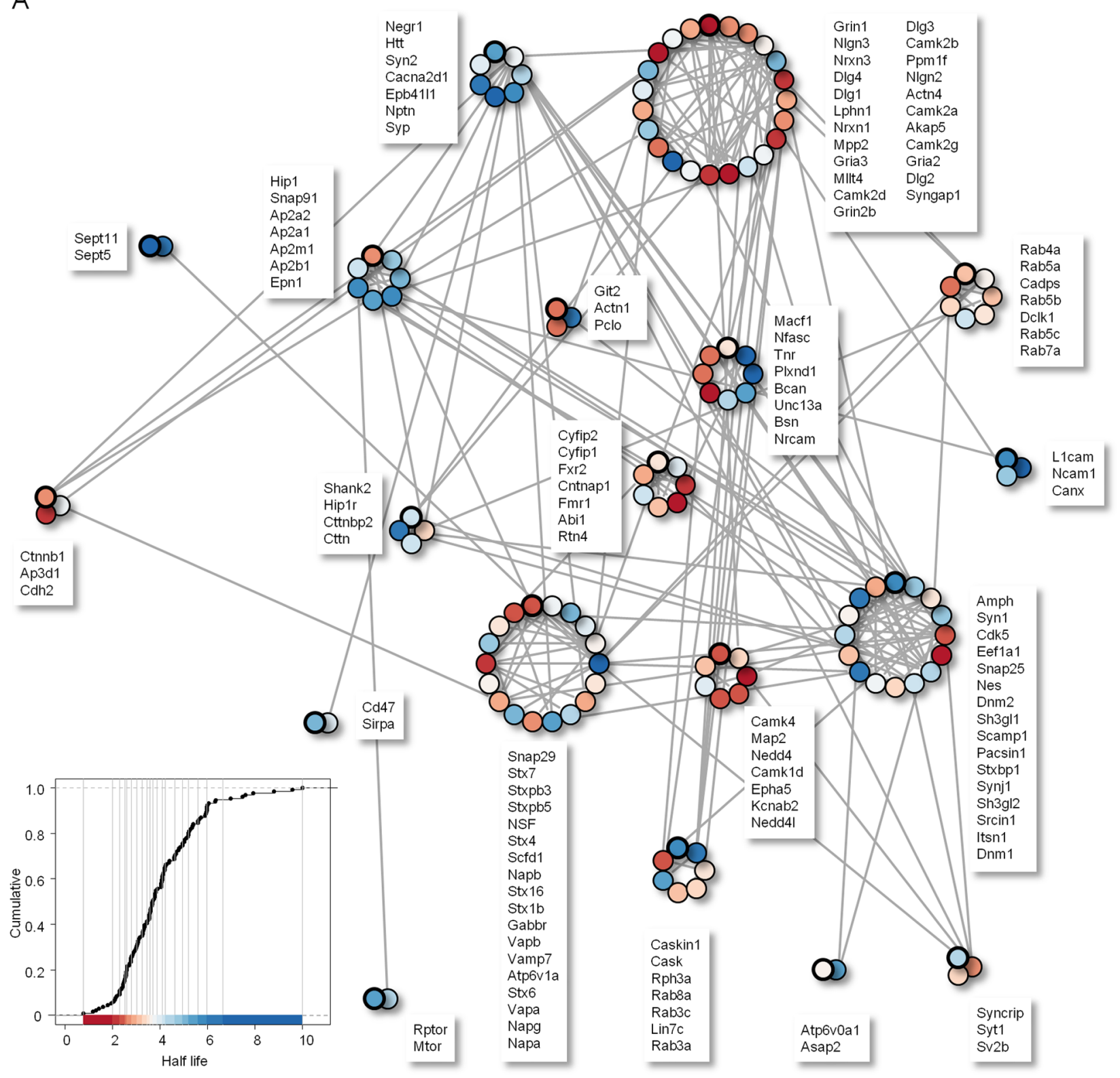

B

All identified proteins found in HIPPIE database $(2,475)$

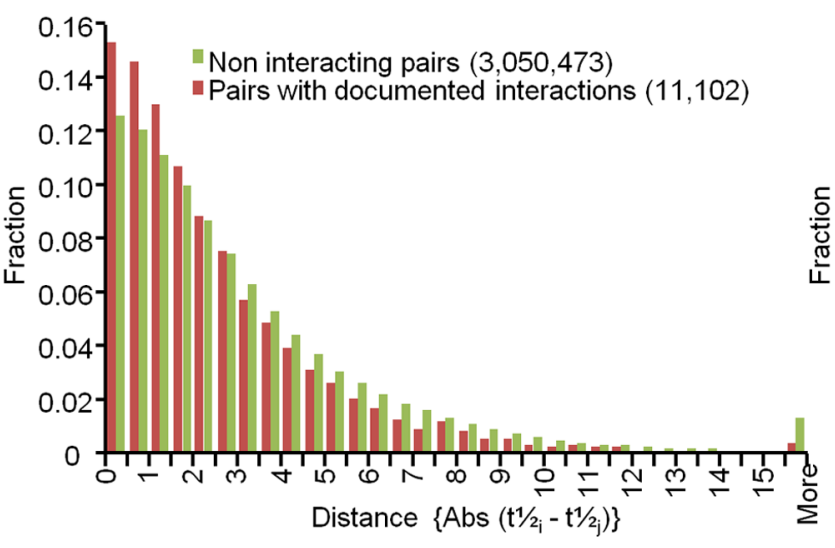

C Synaptic proteins found in HIPPIE database (191)

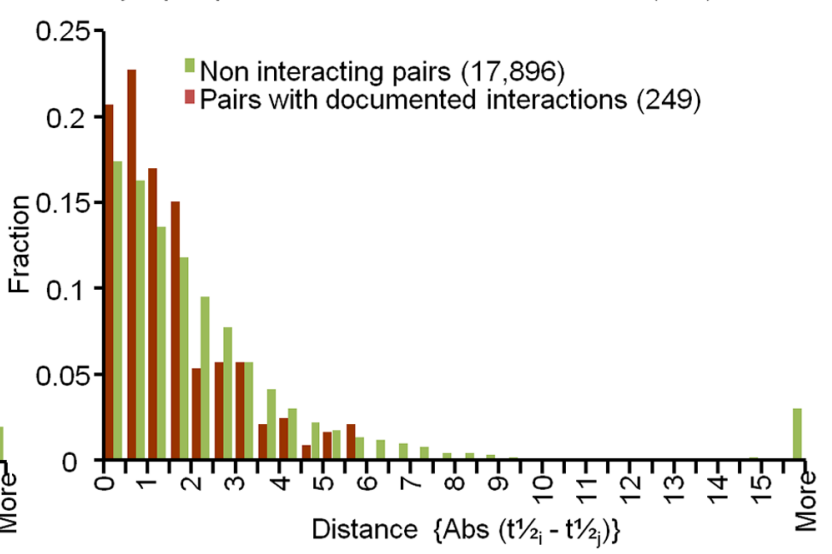


Figure 7. Relationships between half-life estimates and protein-protein interaction groups. A) A molecular interaction network of 191 synaptic related proteins (main text and Table 1) generated on the basis of a manually curated public domain protein-protein interaction database (Human Integrated Protein-Protein Interaction Reference, or HIPPIE; [55]; see Materials and Methods for further details). Each circle represents one protein, with the estimated metabolic half-life for that protein color coded according to the legend at the bottom left corner. Proteins in each cluster are listed in clockwise fashion, with the top protein in each list referring to the circle in each cluster encompassed with a thick line. B,C) Differences between metabolic turnover rates are smaller on average for pairs of interacting proteins as compared to pairs of non-interacting proteins. Absolute differences between metabolic half-life estimates for all pairs for which interactions are known to exist were compared to all pairs for which interactions are not known to occur (see main text for details), and the distributions of such differences were plotted for both groups. B) All identified proteins, and C) For the list of synaptic and synaptically related proteins. In both cases, differences between groups were highly significant ( $p$ $\ll 10^{-10}$, Kolmogorov-Smirnov test).

doi:10.1371/journal.pone.0063191.g007

shorter) than those of PSD proteins or proteins for which mRNAs are consistently found in dendrites. Interestingly, GO annotation analysis showed that the half-lives of proteins tagged as axonal were distributed in a manner similar to that of the entire population (Fig. S9C).

Comparisons of metabolic turnover rates for proteins that are structurally or functionally related seemed to indicate that in some cases, their metabolic turnover rates are also very similar. For example Piccolo and Bassoon, two huge presynaptic active zone proteins that share many properties, were found to have nearly identical metabolic turnover rates (half-lives of 2.54 and 2.56 days respectively; Fig. 3). Similarly, GluA2 and GluA3, the major subunits of AMPA-type glutamate receptors, exhibited very similar metabolic turnover rates (half-lives of 1.95 and 2.04 days respectively; Fig. 3). Such similarities are potentially interesting as they might indicate that the biogenesis and degradation of functionally related proteins may be coupled, perhaps at the level of functional complexes or subcellular organelles (fully assembled receptors, units of active zone material, synaptic vesicles, etc.). We therefore performed several in-depth analyses to examine this possibility in a systematic manner.

First we used protein-protein interaction databases to examine the hypothesis that proteins belonging to the same multimolecular complex will exhibit similar turnover rates. To that end, we generated a network from the 191 synaptic and synaptically related proteins mentioned above, based on a manually curated public domain protein-protein interaction database (Human Integrated Protein-Protein Interaction Reference or HIPPIE; [55]; see Materials and Methods for further details). The network was then "pruned" to include only proteins for which metabolic turnover rates were determined here and clustered (Fig. 7A; see Materials and Methods for details). ANOVA of the resulting clusters strongly indicated that the distributions of protein halflives were not identical for all clusters $(p<0.002$; see Materials and Methods) indicating that relationships existed between membership in a cluster and protein half-life. To further explore such relationships, we compared the degree to which turnover rates within clusters were more similar to each other as compared to what might be expected by chance. Given the relatively small number of proteins in our list of synaptic and synaptically related proteins, this was performed on half-lives measured here for proteins listed in two published databases of synaptic proteins [56,57] (see Materials and Methods for further details). This analysis revealed that for small clusters (containing 3 or 4 proteins), half-life estimates were often more similar than would be expected by chance $(\mathrm{p}<0.05$; data not shown). Here too, ANOVA of all clusters indicated that distributions of protein half-lives were not identical for all clusters $(\mathrm{p}<0.05)$.

Using the same database (HIPPIE), we also performed a pairwise analysis, in which we compared the metabolic turnover rates of all protein pairs for which verified protein-protein interactions were listed, to all other pairs for which the same database did not contain strong evidence for such interactions.
The comparison was based on absolute differences between the half-lives of two proteins $i$ and $j$ such that

$$
d_{i, j}=\left|t_{1 / 2} i-t_{1 / 2} j\right|
$$

As shown in Fig. 7B, a comparison of half-life differences from 11,102 pairs with known interactions to 3,050,473 non-interacting pairs revealed that differences between metabolic turnover rates for protein pairs with known interactions were smaller (interacting: mean \pm SEM $2.58 \pm 0.025$, median $=1.86$; non-interacting: mean \pm SEM $3.26 \pm 0.002, \quad$ median $=2.26 ; 2,475$ proteins; $\mathrm{p} \ll 10^{-10}$, Kolmogorov-Smirnov test). An even greater difference emerged when this analysis was limited to the 191 proteins belonging to our synaptic protein list (Fig. 7C; interacting: mean \pm SEM $1.56 \pm 0.083$, median $=1.21$; non-interacting: mean \pm SEM $2.62 \pm 0.030$, median $=1.63 ; 191$ proteins; 249 interaction pairs, 17,896 non interaction pairs; $\mathrm{p} \ll 10^{-10}$, Kolmogorov-Smirnov test). Taken together, these analyses indicate that metabolic turnover rates of interacting proteins, and small protein groups belonging to particular multimolecular complexes, are, in some cases, more similar than would be expected by chance.

As mentioned above, we noted some conspicuous similarities in metabolic turnover rates for functionally related groups of synaptic proteins. The bioinformatic analyses described above might be taken to indicate that such similarities are not accidental. It is thus interesting to point out some further similarities. Beyond those mentioned already for the active zone molecules Piccolo and Bassoon, and for the AMPA receptor subunits GluA2 and GluA3 (which were also very similar to those of NMDA receptor subunits NR1 and NR2B), similar turnover rates were observed for 1) Neuroligin-2, Neuroligin-3, Neurexin-1 and Neurexin-3, proteins involved in important transynaptic interactions [58] (half-lives of 2.56, 2.60, 2.89, 2.61, days respectively); 2) Cortactin, $\alpha$-Actinin and Drebrin - actin-binding proteins linked to dendritic spine regulation [59] (half-lives of 5.98, 6.06, and 6.27 days, respectively) and 3) PSD-95 and PSD-93 (half-lives of 3.67 and 3.80 days, respectively). It is also worth pointing out that half-life coefficients of variation for proteins tightly associated with synaptic vesicles and for active zone proteins were smaller than those of the other groups (Fig. 6), implying tighter distributions of metabolic turnover rates within these groups (see also Fig. 3E). This would be consistent with the possibility that the biogenesis/degradation of (some of) these components might be coupled via common trafficking intermediates [60].

\section{Protein Synthesis Load Imposed by the Need to Maintain Synapses}

Recent studies have provided quantitative information on typical copy numbers of many synaptic proteins at individual synapses (reviewed in [40]) and synaptic vesicles [37,61]. 


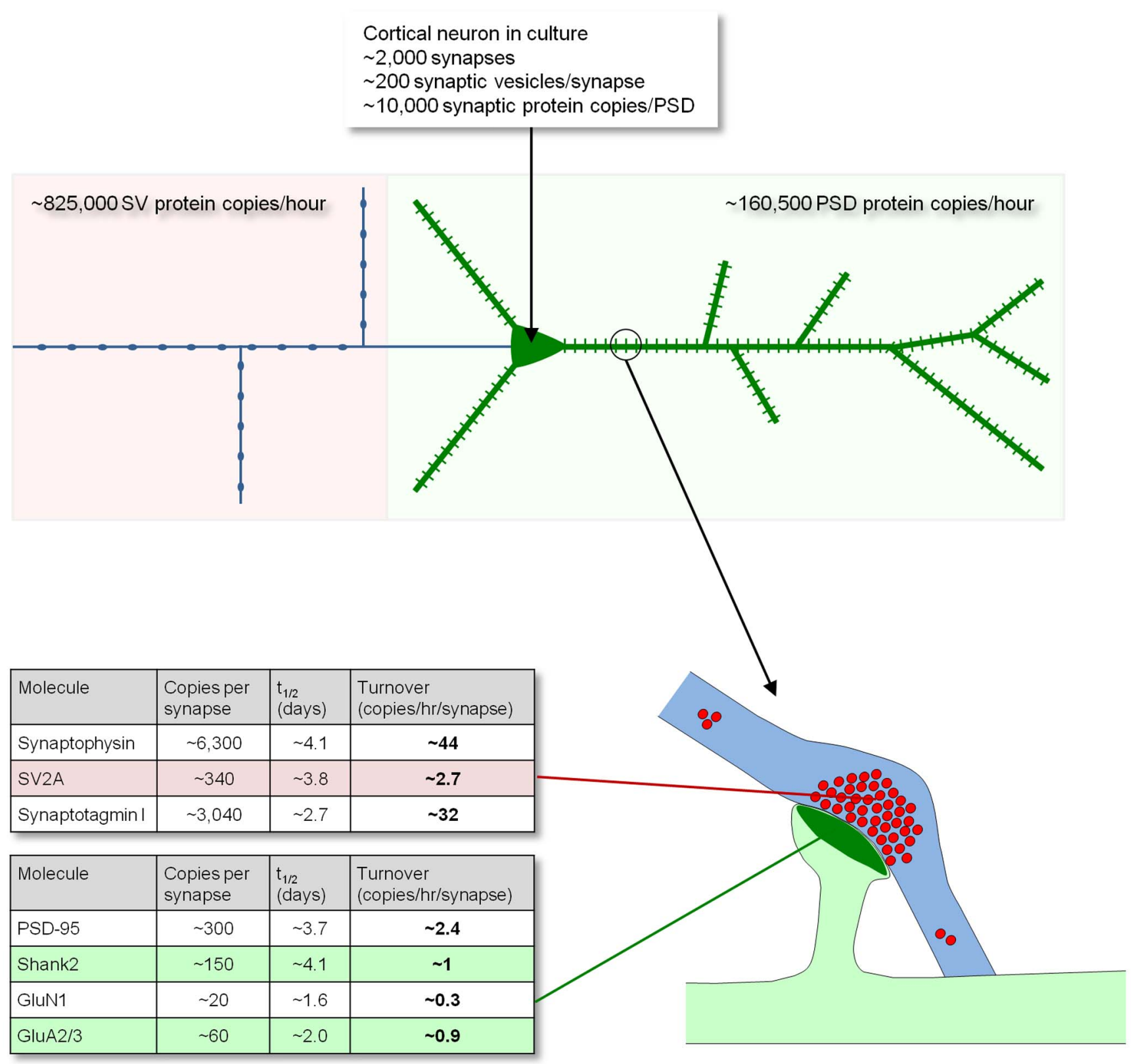

Figure 8. Metabolic load of synaptic protein synthesis. Schematic illustration of a neuron (top) and a synapse (bottom) with some estimates of protein synthesis rates required to maintain the synapse population of a prototypical cortical neuron in primary culture (top) or the synaptic contents of some specific molecules (bottom).

doi:10.1371/journal.pone.0063191.g008

Combining this data with measurements of metabolic turnover rates allows for some estimation of the protein synthesis load that synapses impose on neurons and their biosynthetic machinery.

Reconstruction of neurons expressing a GFP-tagged variant of PSD-95 [33] (Fig. S11) allowed us to estimate the number of glutamatergic synapses made on the dendritic tree of individual cortical neurons in culture to be on the order of 2,000. Using this data, the aforementioned literature on synaptic protein copy number, the assumption that, on average, presynaptic boutons contain $\sim 200$ synaptic vesicles [62] and the assumption that the number of presynaptic boutons an individual neuron has is, on average, identical to the number of synapses it receives, we calculated the daily synthesis rates of some key synaptic proteins in cultured cortical neurons (Fig. 8). For the most abundant synaptic proteins, these rates are very substantial. Thus for example, for the postsynaptic density protein PSD-95 (/SAP90/Dlg4; copies/ synapse $\approx 300)$ synthesis rates are estimated to be $\sim 113,450$ copies per day or $\sim 79$ copies per min. For postsynaptic CaMKII (for which a figure of 5,600 copies/synapse has been reported [40]) synthesis rates are estimated to be $\sim 2,272,200$ copies per day or $\sim 1,580$ copies per min. Similarly, for the synaptic vesicle proteins Synaptophysin and Synaptotagmin 1 (copies/vesicle $\approx 31$ and 15, respectively) synthesis rates are estimated to be $\sim 2,136,300$ and $1,538,400$ copies per day or $\sim 1,484$ and 1,068 copies/min respectively. 
If an average glutamatergic PSD contains $\sim 10,000$ protein copies [40] and the average half-life of PSD proteins is $\sim 3.6$ days (Fig. 6), then for a neuron with 2,000 excitatory synapses, the biosynthesis rate needed to maintain its postsynaptic densities is approximately 3,850,600 protein copies per day, or about 2,670 copies per minute - roughly equivalent to synthesizing the protein content of one PSD every four minutes. For maintaining the pool of synaptic vesicles, assuming that individual synaptic vesicles contain $\sim 250$ protein copies [37] and that the average half-life of synaptic vesicle proteins is $\sim 3.5$ days (Fig. 6), required biosynthesis rates are about 19,802,900 copies per day, or 13,800 copies per minute - equivalent to synthesizing the protein content of $\sim 55$ synaptic vesicles every minute or, put differently, the synaptic vesicle content of one synapse roughly every four minutes. Assuming that all biosynthesis of presynaptic vesicle proteins occurs in the soma, the latter figure predicts that the protein equivalent of about 55 synaptic vesicles is trafficked each minute through the axon initial segment. Given a mean half-life for synaptic proteins of 4.14 days (Fig. 2B), a reasonable approximation would be to summarize that about $0.7 \%$ of the synaptic protein content of these neurons is turned over every hour. This estimate is in good agreement with the loss of $<10 \%$ of synaptic immunofluorescence we observed following exposure to anisomycin for 10 hours (Fig. 5J).

This analysis indicates that maintaining the protein content of a neuron's synapse population places significant demands on its protein synthesis machinery. Given that this analysis was limited to a subset of synaptic proteins (ignoring presynaptic membrane and active zone proteins, calcium channels, and a multitude of nonexclusive synaptic proteins) the protein synthesis load imposed by synapses (in terms of protein copy number) is almost certainly much higher than our estimates suggest.

\section{Discussion}

To gain a better understanding of relationships between protein turnover, synaptic maintenance and remodeling, we used dynamic SILAC, MS, FUNCAT, quantitative immunohistochemistry and bioinformatics to systematically measure the metabolic half-lives of synaptic proteins, to examine how these depend on their cellular localization and on association with particular molecular complexes, and to assess the metabolic load synaptic proteostasis places on individual neurons. In contrast with several recent studies in which half-lives of several hours were reported for a number of major synaptic proteins, we found that nearly all synaptic proteins identified here (191) exhibited half-lifetimes in the range of 2-5 days. Unexpectedly, metabolic turnover rates were not significantly different for presynaptic and postsynaptic proteins, or for proteins for which mRNAs are consistently found in dendrites. Some functionally or structurally related proteins exhibited very similar turnover rates, indicating that their biogenesis and degradation might be coupled, a possibility further supported by bioinformatics-based analyses. Our findings suggest that $\sim 0.7 \%$ of the synaptic protein content of the neurons studied here is turned over every hour, and that this turnover places a substantial load on the neuronal biosynthetic and transport mechanisms. The implications of these findings are discussed below.

\section{Methodological Considerations}

Our estimates of protein half-lives were based on several assumptions, some of which warrant discussion.

First, we assumed that the total amount $(\mathrm{H}+\mathrm{L})$ of each protein species remained constant and thus, incorporation rates repre- sented the complement of degradation rates. As we and others have noted, however, synapse numbers tend to increase at moderate rates during the one week period used here. Indeed, we measured a $27 \%$ increase in synaptic numbers over this period (Fig. S5A,B). Consequently this would lead to a small overestimation of actual turnover rates, as illustrated in Fig. S5C,D. On the other hand, the fraction of synaptic proteins in neuronal extracts barely increased during this period (Fig. S6) and no significant differences were observed when turnover rates during the third week and fourth weeks in vitro were compared (Fig. S7). We therefore surmise that the modest growth in synaptic numbers did not severely affect our half-life estimates and in any case would not result in underestimates of turnover rates.

Second, we assumed that heavy AA incorporation would follow single exponential kinetics. While Figs. 1C, 3A-D and S3 generally support this assumption, in a minority of cases fits to single exponential functions were less than perfect. This might be due to several reasons: 1) H/L ratio inaccuracies (due to peptide identification or quantification errors); 2) Multiple pools of protein species that differ greatly in their turnover rates; 3) Changes in turnover rates over the seven-day experiment period. Proteins for which fits were very poor were excluded $(2 \%)$, but for some of the remaining identified proteins $(\sim 6 \%$; Fig. S3) fits were imperfect and thus estimates for these proteins might be less accurate than desirable.

Our third assumption was that the majority of synaptic proteins subjected to MS analysis originated from synaptically localized pools. Immunolabeling here (Fig. 5, Fig S5A) and elsewhere indicates that in these preparations, the majority of PSD, CAZ and synaptic vesicle proteins are localized to synaptic junctions. As mentioned in the introduction, however, imaging studies indicate that synaptic proteins continuously move between synaptic and extrasynaptic pools [18-24] at rates that greatly exceed their metabolic turnover rates (see below). These dynamics imply that the distinction between synaptic and extrasynaptic pools becomes blurred over the time scales of these experiments (days) and thus metabolic turnover rates measured here probably represent some combination of turnover rates for synaptic and extrasynaptic proteins.

One last point that deserves explicit mention is that the cell culture preparations used here contained glial cells. Thus, for proteins that are not specific to neurons, reported rates reflect a combination of turnover rates in neurons and glia.

\section{Implications for Synapse Biology}

To obtain a realistic understanding of synaptic maintenance and to constrain hypotheses regarding relationships between synaptic plasticity and protein synthesis/degradation, reliable estimates of synaptic protein metabolic turnover rates are essential. To date, few attempts have been made to systematically measure such rates. One notable study is that of Ehlers (2003) [3] in which ${ }^{35} \mathrm{~S}$ pulse-chase labeling was used to measure metabolic turnover rates in cultured rat cortical neurons. The study reported an average $t_{1 / 2}$ for total PSD proteins of 3.25 hours $(\tau=4.7$ hours) and an average $t_{1 / 2}$ for 10 specific PSD proteins of $<10$ hours $(\tau \approx 13.5$ hours). The half-lives reported for these proteins were much shorter than those reported here \{for example NR1:13 h vs. $38 \mathrm{~h}$; Dlg3/SAP102:7 h vs. 51 h; Dlg4/PSD-95:8 h vs. 88 h; CaMKII $\beta-2: 14$ h vs. $91 \mathrm{~h}$; Ehlers (2003) [3] vs. current data, respectively $\}$. It is important to note, however, that the relatively short $(12 \mathrm{~h})$ "pulse" period used in the aforementioned study would strongly bias estimates towards pools with fast turnover rates, because proteins and protein pools with slow turnover rates would barely become labeled and thus, would be underrepresent- 
ed in subsequent chase periods. Indeed, our FUNCAT experiments, in which the pulse duration was 24 hours, resulted in somewhat shorter estimates of global protein turnover rates (Fig. 4) as compared to those obtained in our SILAC experiments in which the "pulse" period was much longer (7 days). As a result, our SILAC experiments were probably less biased toward protein pools with rapid metabolic turnover rates.

In a more recent study [63] organism-wide isotopic labeling and MS were used to compare protein turnover rates in mouse brain, liver and blood tissues. Labeling was achieved by providing adult mice with a diet supplemented with ${ }^{15} \mathrm{~N}$-enriched algae. Unlike dynamic SILAC, where labeled AA introduction is abrupt and temporally well defined, labeling in that approach is protracted and much less controlled. Consequently, turnover estimations require corrections for $\mathrm{AA}$ ingestion, excretion, internal metabolism and catabolism kinetics. Nevertheless, it is interesting to compare estimates of turnover rates for synaptic proteins identified in that study to those obtained here. As a rule, these estimates were much slower (e.g. Synaptophysin: 502 h vs. 98 h; Bassoon: $240 \mathrm{~h}$ vs. 62 h; GluA2:173 h vs. 47 h; Dlg4/PSD-95:367 h vs. 88 h; CaMKII $\beta-2: 157$ h vs. 91 h; [63] vs. current data, respectively). Perhaps here too, the longer "pulse" period (32 days) exposed additional pools with even slower turnover rates (see [64]). Assuming these differences are not due to methodological issues, this study might indicate that turnover rates of synaptic proteins in adult mice are even slower than those reported here (compare also [65] and [66], to [67] for AMPA receptor subunits). Interestingly, a comparison with protein turnover in HeLa cells [32] shows that protein turnover in primary cultures of cortical neurons is generally slower than that observed in this immortalized cell line.

It is generally thought that the bulk of synaptic proteins is synthesized in the cell body and thereafter transported to synaptic sites. The transport of many synaptic proteins can be rather slow (millimeters/day; [5-8]). The relatively slow turnover rates reported here are quite compatible with such transport rates. On the other hand, if synaptic protein turnover is as rapid as previously suggested for PSD proteins (such as PSD-95; $\mathrm{t}_{1 / 2} \approx 8 \mathrm{~h}$ [3]) or for the presynaptic active zone protein $\operatorname{Riml}\left(\mathrm{t}_{1 / 2} \approx 0.7 \mathrm{~h}\right.$; [4]), some way of reconciling rapid turnover with slow transport is called for [16]. It is worth noting that in our hands, synaptic Rim and PSD-95 levels were reduced by only 8\% and 10\% following $10 \mathrm{~h}$ exposures to anisomycin (Fig. 5G,I), in better agreement with an estimate of El-Husseini and coworkers [68] for PSD-95 $\left(\mathrm{t}_{1 / 2} \approx 36 \mathrm{~h}\right)$.

Discrepancies between turnover and trafficking rates might possibly be resolved by reconsidering the roles of local protein synthesis in dendrites [9-12] and axons [13,14,16]. Although these are usually discussed in the context of synaptic plasticity, perhaps their primary role is to maintain the synaptic contents of (remote) synapses [16]. In this respect it is interesting to note that no major differences were observed in the average turnover rates of presynaptic (axonal) or postsynaptic (dendritic) proteins, in spite of their very different distances from the cells' major biosynthetic center, i.e. the soma, nor were these different for proteins for which synthesis is assumed to occur in dendrites (Fig. 6). Given the relatively slow turnover rates of synaptic proteins reported here, local protein synthesis rates need not be very high. At the extreme, if polyribosomes located near spines (e.g. $[69,70])$ are to synthesize the entire protein contents of $2-8$ PSDs $(\sim 20,000$ to 80,000 molecules [40]), and if the average half-life of postsynaptic proteins is $\sim 3.5 \mathrm{~d}$, synthesis rates would need to be $\sim 240$ to $\sim 960$ copies/ hour or $\sim 4$ to $\sim 16$ copies $/ \mathrm{min}$. More realistically, however, local synthesis might mainly be important for supplying proteins with relatively high turnover rates, such as glutamate receptor subunits (Fig. 3; see [48]).

As mentioned above, live imaging studies based on fluorescence recovery after photobleaching (FRAP), photoactivation and single particle tracking consistently suggest that synaptic molecules continuously move into, out of and between synapses at fairly rapid rates (reviewed in [18-24]). In comparison to metabolic halflives, residency half-lives are orders of magnitude shorter (Synapsin-1: $\sim 1 \mathrm{~h}$ vs. $\sim 4.9$ days; Bassoon: $\sim 3 \mathrm{~h}$ vs. $\sim 2.6 \mathrm{~d}$, Munc-13-1: $\sim 1 \mathrm{~h}$ vs. $\sim 1.3 \mathrm{~d}$; PSD-95: $\sim 3.3 \mathrm{~h}$ vs. $\sim 3.7 \mathrm{~d}$; residency vs. metabolic turnover half-lives, respectively $[7,71,72,73])$; these differences become even more apparent when considering the short residency times of integral membrane proteins (e.g. [22,24,74]). The predominance of exchange rates over metabolic turnover rates [7] would seem to have two fundamental implications: First, it would seem to suggest that the availability of many, if not most, synaptic proteins is not a limiting factor when rapid changes in synapse composition and size are required, simply because synaptic components can be recruited from nearby synapses, in a manner similar to that observed during synaptogenesis (e.g. [75-77]). Second, it would seem to question the ability of local synthesis and degradation processes to regulate the composition of individual synapses in isolation from neighboring synapses, because proteins added to one synapse might migrate to neighboring ones. It should be noted, however, that the generality of protein exchange predominance over metabolic turnover is yet to be determined, given that some dendritic proteins exhibit higher metabolic turnover rates (e.g. Fig. 4, [35]). It is possible that such proteins escaped detection here due to, for example, relatively low abundance [78]. Perhaps scarce proteins, synthesized locally, play crucial roles in determining synaptic properties on time scales that are faster than protein exchange rates $[79,80]$. We expect that future studies, using new techniques to identify and localize newly synthesized proteins [81], will gradually clarify the physiological relationships between protein exchange, protein turnover, and synaptic plasticity.

\section{Materials and Methods}

\section{Ethics}

All experiments were performed in primary cultures of rat neurons prepared according to a protocol approved by the "Technion, Israel Institute of Technology Committee for the Supervision of Animal Experiments" (ethics approval number IL099-08-10).

\section{Cell Culture}

Primary cultures of rat cortical neurons used for SILAC experiments were prepared as described previously [33]. Briefly, cortices of 1-2 days-old Wistar rats of either sex were dissected, dissociated by trypsin treatment followed by trituration using a siliconized Pasteur pipette. $1.2 \cdot 10^{6}$ cells were then plated in 12-well plates whose surface had been pretreated with polyethylenimine (Sigma) to facilitate cell adherence. Cells were initially grown in medium containing minimal essential medium (MEM; Sigma), $25 \mathrm{mg} / \mathrm{l}$ insulin (Sigma), $20 \mathrm{mM}$ glucose (Sigma), $2 \mathrm{mM} \mathrm{L-}$ glutamine (Sigma), $11.16 \mathrm{mg} / \mathrm{l}$ gentamycin sulfate (Sigma), 10\% NuSerum (Becton Dickinson Labware), and 0.5\% fetal bovine serum (HyClone). The preparation was then transferred to a humidified tissue culture incubator and maintained at $37^{\circ} \mathrm{C}$ in a $95 \%$ air and $5 \% \mathrm{CO}_{2}$ mixture. Half the volume of the culture medium was replaced three times a week with feeding medium similar to the medium described above but devoid of NuSerum, 
containing a lower concentration of L-glutamine (Sigma, $0.5 \mathrm{mM}$ ), and 2\% B-27 supplement (Gibco).

Primary cultures of rat hippocampal neurons for protein synthesis inhibition experiments were prepared as described previously [7]. In brief, hippocampal CA1-CA3 regions of 1-2 days-old Wistar rats of either sex were dissected and dissociated as described above and plated onto $22 \times 22 \mathrm{~mm}$ coverslips coated with poly-D-lysine (Sigma) inside 8-mm-diameter glass cylinder (Bellco Glass) microwells. Culture medium consisted of minimal essential medium (MEM; Gibco), $20 \mathrm{mM}$ glucose, $0.1 \mathrm{~g} / \mathrm{l}$ bovine transferrin (Calbiochem), $25 \mathrm{mg} / \mathrm{l}$ insulin (Sigma), $2 \mathrm{mM} \mathrm{L-}$ glutamine (Sigma), 10\% NuSerum (Becton Dickinson Labware), $0.5 \%$ fetal bovine serum (HyClone), 2\% B-27 supplement (Gibco), and $8 \mu \mathrm{M}$ cytosine $\beta$-D-arabinofuranoside (Sigma) which was added to the culture medium after $3 \mathrm{~d}$. Cultures were maintained at $37^{\circ} \mathrm{C}$ in a $95 \%$ air and $5 \% \mathrm{CO}_{2}$ humidified incubator. Culture medium was replaced every $7 \mathrm{~d}$.

Primary cultures of rat hippocampal neurons for FUNCAT (FlUorescent Non-Canonical Amino acid Tagging) experiments were essentially prepared as described previously [82]. Cells were prepared from E18 brains of Wistar rats (either sex), raised in the animal facility of the Leibniz Institute for Neurobiology, dissociated in $\mathrm{Ca} 2+$ and $\mathrm{Mg} 2+$ free Hank's balanced salt solution with $0.25 \%$ Trypsin and plated on Poly-D-lysine coated glass coverslips at desired densities in DMEM including 10\% fetal calf serum, $2 \mathrm{mM}$ glutamine, and antibiotics (100 U/ml penicillin, $100 \mu \mathrm{g} / \mathrm{ml}$ streptomycin, $250 \mathrm{ng} / \mathrm{ml}$ Fungizone ${ }^{\circledR}$ ) (all Invitrogen) and kept in humidified atmosphere at $37^{\circ} \mathrm{C}$ and $5 \% \mathrm{CO}_{2}$. The medium was replaced $24 \mathrm{~h}$ later with Neurobasal medium supplemented with B27, $0.8 \mathrm{mM}$ glutamine and antibiotics.

\section{SILAC}

After cortical cells were grown for 14 days, media containing heavy isotope-labeled variants of lysine $\left\{\right.$ Lys8, $\left.\left({ }^{13} \mathrm{C}_{6},{ }^{15} \mathrm{~N}_{2}\right)\right\}$ and arginine $\left\{\operatorname{Arg} 10,\left({ }^{13} \mathrm{C}_{6},{ }^{15} \mathrm{~N}_{4}\right)\right\}$ (Cambridge Isotope Laboratories) was added to the culture dishes, resulting in an excess of heavy lysine and arginine (5:1) as compared with the non-labeled variants of these amino acids. Neurons were harvested immediately (time 0 ) and after 1, 3, and 7 days. For preparations maintained for 3 and 7 days before harvesting, the feeding media used contained heavy lysine and arginine at concentrations that preserved the 5:1 heavy to light $(\mathrm{H} / \mathrm{L})$ ratios. Harvesting was done by gently washing the cells 3 times in a physiological solution ("Tyrode's", $119 \mathrm{mM}$ $\mathrm{NaCl}, 2.5 \mathrm{mM} \mathrm{KCl}, 2 \mathrm{mM} \mathrm{CaCl} 2,2 \mathrm{mM} \mathrm{MgCl}_{2}, 25 \mathrm{mM}$ HEPES, $30 \mathrm{mM}$ glucose, buffered to $\mathrm{pH} 7.4$ ), aspirating all the solution, and immediately adding $100 \mu \mathrm{l}$ of lysis buffer composed of $10 \%$ sodium dodecyl sulfate (SDS; Sigma), $30 \mathrm{mM}$ TRIS $\mathrm{HCl}$ (Sigma), 3.4\% glycerol, $25 \mathrm{mM} \mathrm{DTT} \mathrm{(Sigma),} \mathrm{and} \mathrm{0.5 \%} \mathrm{v/v}$ protease inhibitor (Calbiochem). The cells were then scraped in the lysis buffer using a disposable cell scraper. The lysate was then collected, pipetted vigorously on ice, boiled for $5 \mathrm{~min}$, and frozen at $-80^{\circ} \mathrm{C}$ until used.

For "conventional" SILAC experiments, the cells were grown in lysine and arginine-free MEM (Biological Industries) to which Lys8 and Arg10 were added ( $0.4 \mathrm{mM}$ and $0.6 \mathrm{mM}$ respectively). After two weeks, cells were gently washed by partial replacement of media with lysine and arginine-free media to which lysine and arginine (Sigma) were added at identical concentrations. Following 3 washes, conditioned media from "sister" preparations (grown in media containing light AAs which were never exposed to heavy AA) was added. Cells were harvested and processed at days 0, 1, 3, and 7 as described above.

\section{Labeling Newly Synthesized Proteins, FUNCAT and Immunocytochemistry}

The medium of primary cultures hippocampal neurons prepared as described above (21 days in culture) was exchanged to methionine-free Hibernate-medium [83] supplemented with B27, $0.8 \mathrm{mM}$ glutamine, antibiotics (100 U/ml penicillin, $100 \mu \mathrm{g} /$ $\mathrm{ml}$ streptomycin, $250 \mathrm{ng} / \mathrm{ml}$ Fungizone $^{\circledR}$ ) and $4 \mathrm{mM}$ AHA (prepared according to [84]). Cells were either washed with PBS-MC ( $1 \mathrm{mM} \mathrm{MgCl}_{2}, 0.1 \mathrm{mM} \mathrm{CaCl}$ ) at $\mathrm{pH} 7.4$ and fixed with $4 \%$ paraformaldehyde in PBS for $5 \mathrm{~min}$ at room temperature or cultivated in methionine-free Hibernate-medium supplemented with B27, $0.8 \mathrm{mM}$ glutamine, antibiotics and $4 \mathrm{mM}$ methionine and fixed after $24 \mathrm{~h}$ or $48 \mathrm{~h}$. The FUNCAT procedure was carried out as described previously [35] with minor changes. Fixed cells were incubated in B-block solution (10\% horse serum, $5 \%$ sucrose, $2 \%$ bovine serum albumin, $0.1 \%$ Triton X-100) for $1.5 \mathrm{~h}$ and washed three times for $10 \mathrm{~min}$ with PBS pH 7.8. Coverslips were incubated in a "click-reaction"-mixture composed of $200 \mu \mathrm{M}$ TBTA, $500 \mu \mathrm{M}$ TCEP and $200 \mathrm{nM}$ Tetramethylrhodamine (TAMRA)-alkyne-tag (Invitrogen) upside-down protected from light at room temperature overnight. Coverslips were washed as described [35] and incubated with primary antibodies diluted in B-block solution for $2 \mathrm{~h}$ at room temperature, washed three times with PBS pH 7.4 and incubated subsequently with Alexa-488 or Cy5-conjugated secondary antibodies in B-block solution for $1 \mathrm{~h}$ at room temperature. Mounting was done using Mowiol-solution (Calbiochem). The following antibodies were used for immunocytochemistry staining in concentrations as indicated: MAP2 (1:1000, Sigma-Aldrich), Synaptophysin (1:2000, SYnaptic SYstems). Fluorescently labeled secondary antibodies (Jackson Laboratories) were used as follows: Alexa 488 conjugated anti-rabbit (IgG, 1:1000), Cy-5 conjugated anti-guinea pig (IgG, 1:1000).

\section{Immunolabeling Against Synaptic Proteins Following Protein Synthesis Inhibition}

At 14 days in culture, primary hippocampal cultures prepared as described above were treated with $25 \mu \mathrm{M}$ anisomycin (Sigma) or vehicle. The cells were fixed after $10 \mathrm{~h}$, and stained using antibodies for synaptic proteins. As a positive control we examined the effect of anisomycin application on c-fos expression. To that end, cells were treated with $25 \mu \mathrm{M}$ of anisomycin or vehicle only for $2 \mathrm{~h}$ and then either exposed to $10 \mu \mathrm{M}$ glutamate or not (as these neuronal networks are spontaneously active) for $2 \mathrm{~h}$. The cells were then fixed and stained against c-fos. The fraction of cells in which bright nuclear c-fos immunolabeling was visible was then quantified.

Immunolabeling was performed by washing the cells in Tyrode's solution followed by fixation with $4 \%$ paraformaldehyde (PFA) and $120 \mathrm{mM}$ sucrose in PBS (fixative solution) for $20 \mathrm{~min}$, or cold $\left(-18^{\circ} \mathrm{C}\right)$ methanol for $5 \mathrm{~min}$. PFA-fixed cells were permeabilized for $10 \mathrm{~min}$ in fixative solution to which $0.25 \%$ Triton X-100 (Sigma) was added. The cells were washed three times in PBS, incubated in $10 \%$ bovine serum albumin (BSA, Sigma) for $1 \mathrm{~h}$ at $37^{\circ} \mathrm{C}$, and incubated overnight at $4^{\circ} \mathrm{C}$ with primary antibodies in PBS and 1\% BSA. The cells were then washed three times for 5 min with PBS and incubated for $1 \mathrm{~h}$ at room temperature with secondary antibodies in PBS and 1\% BSA. The cells were washed again with PBS three times, and imaged immediately.

Primary antibodies included: mouse anti-synapsin I 1:400 (TransLabs); mouse anti-PSD-95, clone 108E5 1:150 (Synaptic Systems); mouse anti-PSD-95, 1:500 (Upstate); rabbit anti-SV2A 1:500 (Synaptic Systems); monoclonal anti-bassoon 1:400 (a 
generous gift of Craig Garner, Stanford University); guinea-pig anti-ProSAP2 1:800; rabbit anti-ProSAP1 1:2000 (both generous gifts of Tobias M. Boeckers, Ulm University, Germany); rabbit anti-piccolo 1:200 (a generous gift of Dr. Wilko Altrock, Leibniz Institute for Neurobiology, Magdeburg, Germany); mouse antiRIM 1:200 (BD Transduction Laboratories); rabbit anti-VGAT (Synaptic Systems) 1:200; rabbit anti-c-fos antibody 1:400 (sc-52, Santa Cruz). Secondary antibodies included: AlexaFluor $633 \mathrm{~nm}$ goat anti-mouse IgG2a (Invitrogen), Cy5 donkey anti-mouse (Jackson ImmunoResearch Laboratories), Cy5 donkey anti-guinea pig (Jackson ImmunoResearch Laboratories), Cy5 donkey antirabbit (Jackson ImmunoResearch Laboratories). All secondary antibodies were used at a dilution of 1:200.

\section{In Gel Proteolysis and Mass Spectrometry Analysis}

$48 \mu \mathrm{g}$ of protein from each time point were separated on $7 \%$ SDS-PAGE (Polyacrylamide Gel Electrophoresis; two lanes for each time point) and sliced into 9 sections, including the stacking gel as shown in Fig. 1A. The proteins in each gel slice were reduced with $2.8 \mathrm{mM}$ DTT $\left(60^{\circ} \mathrm{C}\right.$ for $\left.30 \mathrm{~min}\right)$, modified with $8.8 \mathrm{mM}$ iodoacetamide in $100 \mathrm{mM}$ ammonium bicarbonate (in the dark, room temperature for $30 \mathrm{~min}$ ) and digested in $10 \%$ acetonitrile and $10 \mathrm{mM}$ ammonium bicarbonate with modified trypsin (Promega) overnight at $37^{\circ} \mathrm{C}$.

The resulting tryptic peptides were resolved by reverse-phase chromatography on 0.075 X $200-\mathrm{mm}$ fused silica capillaries (J\&W) packed with Reprosil reversed phase material (Dr Maisch GmbH, Germany). The peptides were eluted with linear 95 minute gradients of 7 to $40 \%$ and 8 minutes at $95 \%$ acetonitrile with $0.1 \%$ formic acid in water at flow rates of $0.25 \mu \mathrm{l} / \mathrm{min}$. Mass spectrometry was performed by an ion-trap mass spectrometer (Orbitrap, Thermo) in a positive mode using repetitively full MS scan followed by collision induced dissociation of the 7 most dominant ions selected from the first MS scan.

The mass spectrometry data were analyzed using MaxQuant 1.2.2.5 (Max-Planck Institute for Biochemistry, Martinsried, Germany [29]) searching against the Rattus section of the NCBI-NR database with a false discovery rate of $1 \%$. H/L ratios for all peptides belonging to a particular protein species were pooled, providing an average $\mathrm{H} / \mathrm{L}$ ratio for each protein.

\section{Data Analysis}

Data from two full four time point experiments and two single time point repeats $(\mathrm{t}=3 \mathrm{~d})$ were pooled, with consolidation based on GI entries. For each protein at each time point, a weighted average of $\mathrm{H} / \mathrm{L}$ ratios was calculated, with weights based on the number of peptides identified in each repeat. H/L ratios $\left(H_{t} L_{t}\right)$ for all time points $(t)$ were converted into fractional incorporation ratios $(F t)$ and corrected to the maximal expected ratio $F_{\max } \approx 5 /$ $(5+1)$ according to

$$
\mathrm{F}_{\mathrm{t}}=\frac{1}{F_{\max }} \cdot \frac{H_{t}}{H_{t}+L_{t}}
$$

The data were then fit to exponential curves such that

$$
F_{t}(t)=1-e^{-t / \tau}
$$

with $\tau$ representing the time constant of metabolic protein turnover. $\tau$ values were converted to half-life $\left(t_{1 / 2}\right)$ as follows $t_{1 / 2}=\ln (2) \cdot \tau$. Proteins for which at least 1 peptide was identified from each of the four time points were included in the analysis.
Goodness of fit to exponential curves was judged by the sum of square errors (SSE) values (Fig. S3). Proteins for which SSE $>0.1$ were excluded from further analysis $(\sim 2 \%)$. For the set of synaptic proteins, the exclusion threshold was set to SSE $>0.08$. Analysis was done using Matlab (Mathworks) and Microsoft Excel. For Gene ID conversion, BioDBnet (http://biodbnet.abcc.ncifcrf.gov/ [85]) was used.

\section{Microscopy and Image Analysis}

Imaging of immunolabeled neurons in protein synthesis inhibition experiments was performed using a custom designed confocal laser scanning microscope [7] using a 40X, 1.3 NA Fluar objective. Excitation was performed at $633 \mathrm{~nm}$ (Helium Neon Laser). Fluorescence emissions were read using a $650 \mathrm{~nm}$ longpass filter (Semrock). Images were collected by averaging six frames at two to four focal planes spaced $0.8 \mu \mathrm{m}$ apart. All data were collected at a resolution of $640 \times 480$ pixels, at 12 bits per pixel. Image analysis was performed using custom written software (OpenView) written by N.E.Z. Analysis was performed on maximal intensity projections of 2 sections, located $0.8 \mu \mathrm{m}$ apart. Intensities of fluorescent puncta were measured by programatically centering $9 \times 9$ pixel regions of interest obtaining the average fluorescence intensity in each area as shown in Fig. 5F. Analysis of somatic immunofluorescence was performed using NIH Image J by manually placing regions of interest on somata, excluding the nuclei.

Images of immunolabeled neurons in FUNCAT experiments were acquired using a Zeiss Observer.Z1 microscope and the AxioVision 4.8 software. Image acquisition and image processing were performed with identical exposure times and settings for each treatment group within one experiment. Images were processed with NIH ImageJ. For quantification of synaptic fluorescence using OpenView, proximal dendritic segments were selected with a fixed length of $30 \mu \mathrm{m}$ for all images analyzed.

\section{Recordings of Network Activity}

Cortical neurons were plated on thin glass multielectrode array (MEA) dishes at densities identical to those used for SILAC experiments (see above). MEA dishes used here contained 59, $30 \mu \mathrm{m}$ diameter, electrodes arranged in an $8 \times 8$ array, spaced $200 \mu \mathrm{m}$ apart. The dishes were covered by a custom designed cap containing a submerged platinum wire loop serving as a ground electrode, heated to $37^{\circ} \mathrm{C}$, and provided with a filtered stream of $5 \% \mathrm{CO}_{2}$ and $95 \%$ air through an inlet in the cap. Network activity was recorded through a commercial 60-channel headstage/ amplifier (Inverted MEA1060, MCS) with a gain of $1024 \times$ and frequency limits of 1-5000 Hz. The amplified signal was further amplified and filtered using a bank of programmable filter/ amplifiers (Alpha-Omega, Nazareth, Israel), multiplexed into 16 channels, and then digitized by two A/D boards (Microstar Laboratories, WA, U.S.A.) at 24 KSamples/sec per channel. Data acquisition was performed using AlphaMap (Alpha-Omega). All data was stored as threshold crossing events with the threshold set to $-20 \mu \mathrm{V}$. Electrophysiological data were imported to Matlab (MathWorks, MA, USA) and analyzed using custom written scripts.

\section{Bioinformatics}

Protein interaction networks were generated using a public domain protein-protein interaction database (HIPPIE; [55]). The network was then "pruned" to include only proteins for which metabolic turnover rates were determined here and clustered using the edge betweenness scoring algorithm ( $\mathrm{R}$ package Igraph; http://igraph.sourceforge.net/screenshots2.html). Single factor ANOVA of the resulting clusters (size 2 and up) was performed 
for both the original half-life estimates and for the logarithms of the values to correct for the skewed (non-normal) distribution of half-life estimates. To examine the degree to which turnover rates within clusters were more similar to each other as compared to what might be expected by chance, 1000 randomized networks of identical architecture but with shuffled turnover rates were analyzed in parallel to the original network. The number of clusters and their composition remains the same for all the networks while the distribution of the values for turnover rates varies. The width of the distribution for those values within a particular cluster was estimated as $V_{q d i s t}=V_{3 r d . Q u}-V_{1 s t . Q u}$, where $V_{3 r d . Q u}$ and $V_{1 s t . Q u}$ correspond to the values for turnover rates for the $3^{\text {rd }}$ and $1^{\text {st }}$ quartiles, respectively. A Kolmogorov-Smirnov test was performed to compare the obtained $V_{\text {qdist }}$ for clusters of equal size for the original network and for 1000 networks with shuffled values.

\section{Supporting Information}

Figure S1 Comparison of MS profiles of labeled and unlabeled samples. Cortical neurons were either grown in the presence of $6 \times$ heavy AAs for 3 days (starting at day 14 in vitro as described in main text and in Materials and Methods) or maintained in standard growth media for the same period (control). Lysates of these preparations were then subjected to MS analysis as described in Fig. 1A. Data are from two duplicates, each subjected to separate MS analysis. A) Gel used to separate proteins according to molecular weight (stained with Coomassie Blue; gel image cropped to remove empty lanes). Two lanes were run for each sample to increase protein amounts. Gels were then sliced as in Fig. 1, proteins in each slice were digested, and resulting peptides from each slice and each duplicate were submitted separately to MS analysis. B, G) Number of peptides identified for each protein. Region in gray box is enlarged in bottom panel. Lines represent linear regressions. Data is the sum of peptide numbers identified for each protein in each duplicate. D,E) Total intensities of peptides identified for each protein. Region in gray box is enlarged in bottom panel. Lines represent linear regressions. Data is the average of intensities measured in duplicates. An excellent correlation was observed between MS profiles of heavy AA treated and control preparations. The deviations of the slopes from 1.0 are well within the range observed when comparing two samples. For example, slopes were 1.09 and 1.00 (peptides and intensities, respectively) for controlcontrol duplicate comparisons and 1.15 and 1.34 for heavy AAheavy AA duplicate comparisons. These differences probably reflect slight differences between the amounts of proteins loaded on the polyacrylamide gels.

(TIF)

Figure S2 Effects of an excess of heavy $\mathrm{AA}$ on network activity. Cortical neurons were grown on multielectrode (MEA) substrates for two weeks in an identical fashion to preparations used for SILAC experiments. The preparations were then mounted on an MEA amplifier as described previously [33]. Spontaneous activity was measured for 3 hours after which heavy AA (Heavy) or standard growth media (Control) were added to the MEA dish in a fashion identical to that performed in SILAC experiments. Recordings were then continued for another 12 hours. Action potentials (spikes) measured from all 60 electrodes were accumulated at $1 \mathrm{~min}$ intervals, the resulting spike rates were averaged over one hour time windows and normalized to mean spike rates during first 3 hours. A large variability was observed between networks, but the addition of heavy AA acids did not seem to have any particular effects.

(TIF)
Figure S3 Distribution of sum of square errors (SSE) for fits to single exponentials. SSE values for all identified proteins for which data was obtained for all four time points $(2,859$ proteins). The lower the SSE value, the better the fit. Note that the fit for the vast majority of proteins was excellent $(\mathrm{SSE}<0.02)$ and only a very small number of proteins $(\sim 2 \%)$ exhibited unacceptable fits (SSE >0.1).

(TIF)

Figure S4 Repeatability of half-life estimations. A) Distributions of half-life estimates obtained separately in two experiments carried out two weeks apart. Only proteins for which data from all 4 time points was obtained in both experiments were included (1,622 proteins). B) Comparison of half-life estimates for individual proteins $(1,608)$. Proteins with half-life estimates exceeding 20 days were excluded. C) Enlargement of region enclosed in gray box in B.

(TIF)

Figure S5 Quantification of synaptic densities at the four time points of the SILAG experiments. Cortical neurons were grown on glass bottom substrates for two weeks in an identical fashion to preparations used for SILAC experiments. The neurons were then fixed after an additional $0,1,3$ or 7 days and stained against the PSD molecule PSD-95. Nine Z sections were then collected at $0.8 \mu \mathrm{m}$ intervals at 14 to 17 fields of view in each dish. Synapses were counted programmatically as shown in Fig. 5 in sections \#2 or \#3 and \#6 or \#7 and counts were summed, and expressed as average count/field of view for all fields of view in two separate experiments. A) Two representative sections and the maximal intensity projection of all 9 sections. Images were taken at 17 days in vitro (i.e., two weeks +3 days in culture). Bar, $10 \mu \mathrm{m}$. B) Changes in synaptic density over the one week period. A mean growth of $\sim 4 \%$ /day in synaptic density was measured. $\mathbf{C}$ ) Illustration of the effect that increases in total amounts of a given protein will have on half-life estimates. Note that the relative fraction of preexisting protein will seem to decrease (right panel) even though it does not change relative to the left panel. D) The anticipated effect of a $4 \%$ growth/day on the half-life estimate for a protein whose "real" half-life is 3.5 days. As shown here, this will lead to an apparent half-life of $\sim 3.0$ days, that is, an overestimation of the turnover rates for this protein.

(TIF)

Figure S6 Fractional intensity of synaptic proteins in SILAC experiments. The intensity measured for all peptides $(\mathrm{H}+\mathrm{L})$ for all synaptic proteins, divided by the intensities measured for all identified proteins. As equal amounts of proteins were loaded on the separation gels, these data indicate that the fraction of synaptic proteins in the protein mixture barely changed over the 7-day experimental period, arguing against a large increase in synaptic numbers during this period.

(TIF)

Figure S7 Comparison of fractional incorporation ratios for neurons maintained in culture for $\mathbf{2}$ weeks and 3 weeks. Cortical neurons were maintained in culture for either 2 weeks or 3 weeks and then exposed to heavy AA for 3 days as described in main text and in Materials and Methods. Lysates of these preparations were then subjected to MS analysis as described in Fig. 1A. The fractional incorporation values were then compared for each protein identified in both data sets $(2,460$ proteins). Note the good correlation between the two data sets and the fact that the slope is $\sim 1.0$.

(TIF) 
Figure S8 Distributions of metabolic half-life estimates obtained by "conventional" dynamic SILAC. Neurons were grown for 2 weeks in lysine and arginine-free MEM to which Lys8 and Arg10 were added at nominal concentrations. After two weeks, cells were washed and placed in conditioned media from "sister" preparations (see Materials and Methods for details). 0, 1, 3 , and 7 days later cells were lysed and processed as described above and half-life estimates were obtained from $\mathrm{H} / \mathrm{L}$ ratios at 4 time points. A) Distribution of half-life estimates for all proteins for which $\mathrm{H} / \mathrm{L}$ ratios were obtained at all 4 time points. Only proteins whose fits to single exponentials were satisfactory (SSE $<0.1)$ were included. B) Comparison of half-life estimates for individual proteins for which data was obtained in both forms of dynamic SILAC experiments (Light $\rightarrow$ Heavy $=$ data of Figs. 1-3; Heavy $\rightarrow$ Light = data of panel A).

(TIF)

Figure S9 Distributions of metabolic half-life estimates of proteins selected according to particular GO annotations. Subsets of proteins were selected according to specific GO annotations and distributions of their metabolic half-life estimates were compared to those of the entire population (2,804 proteins). A) Cell compartment: "Synapse" (105 proteins). B) Cell compartment: "Mitochondrial part" (240 proteins); C) Cell compartment: "Axon" (75 proteins).

(TIF)

Figure S10 Enrichment analysis of proteins longest and shortest metabolic half-life estimates. Lists of all neuronal proteins for which satisfactory half-life estimates were obtained were sorted according to their half-life estimates and subjected to GO based enrichment analysis (according to cellular component) using the public domain tool "GORILLA" (Gene Ontology enRIchment anaLysis and visuaLizAtion tool; [36]; http://cbl-gorilla.cs. technion.ac.il/). Note that enrichment analysis performed by this tool is based only on rank order, not absolute values. A) Enrichment analysis of proteins with longest metabolic half-life estimates. B) Enrichment analysis of proteins with shortest metabolic half-life estimates. The statistical significance of enrichment scores is color coded according to the index on the right hand side.

(TIF)

\section{References}

1. Baitinger C, Willard M. (1987) Axonal transport of synapsin I-like proteins in rabbit retinal ganglion cells. J Neurosci 7: 3723-3735.

2. Petrucci TC, Macioce P, Paggi P (1991) Axonal transport kinetics and posttranslational modification of synapsin I in mouse retinal ganglion cells. J Neurosci 11: 2938-2946.

3. Ehlers MD (2003) Activity level controls postsynaptic composition and signaling via the ubiquitin-proteasome system. Nat Neurosci 6: 231-242.

4. Yao I, Takagi H, Ageta H, Kahyo T, Sato S, et al. (2007) SCRAPPERdependent ubiquitination of active zone protein RIM1 regulates synaptic vesicle release. Cell 130: 943-957.

5. Hoffman PN, Lasek RJ (1975) The slow component of axonal transport. identification of major structural polypeptides of the axon and their generality among mammalian neurons. J Cell Biol 66: 351-366.

6. Vallee RB, Bloom GS (1991) Mechanisms of fast and slow axonal transport. Annu Rev Neurosci 14: 59-92.

7. Tsuriel S, Geva R, Zamorano P, Dresbach T, Boeckers T, et al. (2006) Local sharing as a predominant determinant of synaptic matrix molecular dynamics. PLoS Biol 4: e271.

8. Scott DA, Das U, Tang Y, Roy S (2011) Mechanistic logic underlying the axonal transport of cytosolic proteins. Neuron 70: 441-454.

9. Sutton MA, Schuman EM (2006) Dendritic protein synthesis, synaptic plasticity, and memory. Cell 127: 49-58.

10. Schuman EM, Dynes JL, Steward O (2006) Synaptic regulation of translation of dendritic mRNAs. J Neurosci 26: 7143-7146.

11. Zukin RS, Richter JD, Bagni C (2009) Signals, synapses, and synthesis: How new proteins control plasticity. Front Neural Circuits 3: 14.
Figure S11 Synaptic counts of individual cortical neurons in primary culture. Cortical neurons expressing GFPtagged PSD-95 grown on MEA dishes were used to quantify the number of excitatory synapses (bright dots) formed on cultured cortical neurons plated at the same densities as the preparations used for SILAC experiments. The neurons were imaged at days 19-20 in culture. Top image is from [33]. Bars, $50 \mu \mathrm{m}$. (TIF)

Table S1 List of 2,802 proteins for which satisfactory metabolic half-life estimates were obtained. List was sorted according to half-life estimate value (color coded). Only proteins for which SILAC data was obtained for all 4 time points, and for which fits to single exponentials were acceptable are included in this list. As the data was pooled from multiple experiments data consolidation was necessary. "GI" signifies the protein ID used for such consolidation. "Protein Group (MaxQuant)" signifies the protein groups generated by MaxQuant for MS/MS based protein identifications. "Fraction of heavy AA" is the fractional incorporation of heavy $\mathrm{AA}$ at a particular time point $(\mathrm{H} /(\mathrm{H}+\mathrm{L}))$. " $\tau$ " is the time constant of a single exponential function fit to heavy AA incorporation (in days). " $t_{1 / 2}$ " is the estimated half-life (in days) derived from $\tau$. "SSE" is the sum of square errors for the fits to single exponentials. Maximal accepted SSE value was 0.1 .

(XLSX)

\section{Acknowledgments}

We are grateful to the Smoler Proteomics Center at the Technion, to Larisa Goldfeld for her invaluable technical assistance, to Amir Minerbi for the reconstructions of neurons expressing PSD-95:GFP, to Arie Admon (Technion Faculty of Biology) for his helpful suggestions, to Tali Rosenberg (K. Rosenblum group, University of Haifa, Israel) for biochemical assistance, and to Craig Garner (Stanford University), Tobias Boeckers (Ulm University, Germany) and Wilko Altrock (Magdeburg, Germany) for the provision of primary antibodies.

\section{Author Contributions}

Conceived and designed the experiments: LDG DCD TZ NEZ. Performed the experiments: LDC RZ AM OS. Analyzed the data: LDG OS AM DCD JDA TZ NEZ. Contributed reagents/materials/analysis tools: TZ NEZ. Wrote the paper: LDC OS DCD JDA TZ NEZ.

12. Cajigas IJ, Will T, Schuman EM (2010) Protein homeostasis and synaptic plasticity. EMBO J 29: 2746-2752.

13. Jung H, Yoon BC, Holt CE (2012) Axonal mRNA localization and local protein synthesis in nervous system assembly, maintenance and repair. Nat Rev Neurosci 13: 308-324.

14. Deglincerti A, Jaffrey SR (2012) Insights into the roles of local translation from the axonal transcriptome. Open Biol 2: 120079.

15. Lee SK, Hollenbeck PJ (2003) Organization and translation of mRNA in sympathetic axons. J Cell Sci 116: 4467-4478.

16. Alvarez J, Giuditta A, Koenig E (2000) Protein synthesis in axons and terminals: Significance for maintenance, plasticity and regulation of phenotype. with a critique of slow transport theory. Prog Neurobiol 62: 1-62.

17. Wang DO, Martin KC, Zukin RS (2010) Spatially restricting gene expression by local translation at synapses. Trends Neurosci 33: 173-182.

18. Triller A, Choquet D (2005) Surface trafficking of receptors between synaptic and extrasynaptic membranes: And yet they do move! Trends Neurosci 28: 133139.

19. Staras K (2007) Share and share alike: Trading of presynaptic elements between central synapses. Trends Neurosci 30: 292-298.

20. Specht CG, Triller A (2008) The dynamics of synaptic scaffolds. Bioessays 30: 1062-1074.

21. Renner M, Specht GG, Triller A (2008) Molecular dynamics of postsynaptic receptors and scaffold proteins. Curr Opin Neurobiol 18: 532-540.

22. Gerrow K, Triller A (2010) Synaptic stability and plasticity in a floating world. Curr Opin Neurobiol 20: 631-639. 
23. Staras K, Branco T (2010) Sharing vesicles between central presynaptic terminals: Implications for synaptic function. Front Synaptic Neurosci 2: 20.

24. Opazo P, Sainlos M, Choquet D (2012) Regulation of AMPA receptor surface diffusion by PSD-95 slots. Curr Opin Neurobiol 22: 453-460.

25. Pratt JM, Petty J, Riba-Garcia I, Robertson DH, Gaskell SJ, et al. (2002) Dynamics of protein turnover, a missing dimension in proteomics. Mol Cell Proteomics 1: 579-591.

26. Aebersold R, Mann M (2003) Mass spectrometry-based proteomics. Nature 422: 198-207.

27. Milner E, Barnea E, Beer I, Admon A (2006) The turnover kinetics of major histocompatibility complex peptides of human cancer cells. Mol Cell Proteomics 5: 357-365.

28. Ong SE, Mann M (2006) A practical recipe for stable isotope labeling by amino acids in cell culture (SILAC). Nat Protoc 1: 2650-2660.

29. Cox J, Mann M (2008) MaxQuant enables high peptide identification rates, individualized p.p.b.-range mass accuracies and proteome-wide protein quantification. Nat Biotechnol 26: 1367-1372.

30. Liao L, Park SK, Xu T, Vanderklish P, Yates JR (2008) Quantitative proteomic analysis of primary neurons reveals diverse changes in synaptic protein content in fmrl knockout mice. Proc Natl Acad Sci U S A 105: 15281-15286.

31. Doherty MK, Hammond DE, Clague MJ, Gaskell SJ, Beynon RJ (2009) Turnover of the human proteome: Determination of protein intracellular stability by dynamic SILAC. J Proteome Res 8: 104-112.

32. Schwanhäusser B, Busse D, Li N, Dittmar G, Schuchhardt J, et al. (2011) Global quantification of mammalian gene expression control. Nature 473: 337-342.

33. Minerbi A, Kahana R, Goldfeld L, Kaufman M, Marom S, et al. (2009) Longterm relationships between synaptic tenacity, synaptic remodeling, and network activity. PLoS Biol 7: e1000136.

34. Kaufman M, Corner MA, Ziv NE (2012) Long-term relationships between cholinergic tone, synchronous bursting and synaptic remodeling. PLoS ONE 7: e40980.

35. Dieterich DC, Hodas JJ, Gouzer G, Shadrin IY, Ngo JT, et al. (2010) In situ visualization and dynamics of newly synthesized proteins in rat hippocampal neurons. Nat Neurosci 13: 897-905.

36. Eden E, Navon R, Steinfeld I, Lipson D, Yakhini Z (2009) GOrilla: A tool for discovery and visualization of enriched GO terms in ranked gene lists. BMC Bioinformatics 10: 48.

37. Takamori S, Holt M, Stenius K, Lemke EA, Gronborg M, et al. (2006) Molecular anatomy of a trafficking organelle. Cell 127: 831-846.

38. Schoch S, Gundelfinger ED (2006) Molecular organization of the presynaptic active zone. Cell Tissue Res 326: 379-391.

39. Südhof TC (2012) The presynaptic active zone. Neuron 75: 11-25.

40. Sheng M, Hoogenraad CC (2007) The postsynaptic architecture of excitatory synapses: A more quantitative view. Annu Rev Biochem 76: 823-847.

41. Garner GC, Tucker RP, Matus A (1988) Selective localization of messenger RNA for cytoskeletal protein MAP2 in dendrites. Nature 336: 674-677.

42. Burgin KE, Waxham MN, Rickling S, Westgate SA, Mobley WC, et al. (1990) In situ hybridization histochemistry of $\mathrm{Ca} 2+/$ calmodulin-dependent protein kinase in developing rat brain. J Neurosci 10: 1788-1798.

43. Kleiman R, Banker G, Steward O (1990) Differential subcellular localization of particular mRNAs in hippocampal neurons in culture. Neuron 5: 821-830.

44. Furuichi T, Simon-Chazottes D, Fujino I, Yamada N, Hasegawa M, et al. (1993) Widespread expression of inositol 1,4,5-trisphosphate receptor type 1 gene (Insp3r1) in the mouse central nervous system. Receptors Channels 1: 11-24.

45. Benson DL (1997) Dendritic compartmentation of NMDA receptor mRNA in cultured hippocampal neurons. Neuroreport 8: 823-828.

46. Tongiorgi E, Righi M, Cattaneo A (1997) Activity-dependent dendritic targeting of BDNF and TrkB mRNAs in hippocampal neurons. J Neurosci 17: 9492 9505 .

47. Miller S, Yasuda M, Coats JK, Jones Y, Martone ME, et al. (2002) Disruption of dendritic translation of CaMKIIalpha impairs stabilization of synaptic plasticity and memory consolidation. Neuron 36: 507-519.

48. Ju W, Morishita W, Tsui J, Gaietta G, Deerinck TJ, et al. (2004) Activitydependent regulation of dendritic synthesis and trafficking of AMPA receptors. Nat Neurosci 7: 244-253

49. Huang F, Chotiner JK, Steward O (2005) The mRNA for elongation factor lalpha is localized in dendrites and translated in response to treatments that induce long-term depression. J Neurosci 25: 7199-7209.

50. Iijima T, Imai T, Kimura Y, Bernstein A, Okano HJ, et al. (2005) Hzf protein regulates dendritic localization and BDNF-induced translation of type 1 inositol 1,4,5-trisphosphate receptor mRNA. Proc Natl Acad Sci U S A 102: 1719017195.

51. Cajigas IJ, Tushev G, Will TJ, tom Dieck S, Fuerst N, et al. (2012) The local transcriptome in the synaptic neuropil revealed by deep sequencing and highresolution imaging. Neuron 74: 453-466.

52. Steward O, Schuman EM (2003) Compartmentalized synthesis and degradation of proteins in neurons. Neuron 40: 347-359.

53. Martin KC, Zukin RS (2006) RNA trafficking and local protein synthesis in dendrites: An overview. J Neurosci 26: 7131-7134.

54. Bramham CR, Wells DG (2007) Dendritic mRNA: Transport, translation and function. Nat Rev Neurosci 8: 776-789.
55. Schaefer MH, Fontaine JF, Vinayagam A, Porras P, Wanker EE, et al. (2012) HIPPIE: Integrating protein interaction networks with experiment based quality scores. PLoS One 7: e31826.

56. Bayés A, van de Lagemaat LN, Collins MO, Croning MD, Whittle IR, et al. (2011) Characterization of the proteome, diseases and evolution of the human postsynaptic density. Nat Neurosci 14: 19-21.

57. Pielot R, Smalla KH, Muller A, Landgraf P, Lehmann AC, et al. (2012) SynProt: A database for proteins of detergent-resistant synaptic protein preparations. Front Synaptic Neurosci 4: 1.

58. Südhof TC (2008) Neuroligins and neurexins link synaptic function to cognitive disease. Nature 455: 903-911.

59. Pontrello CG, Ethell IM (2009) Accelerators, brakes, and gears of actin dynamics in dendritic spines. Open Neurosci J 3: 67-86.

60. Ziv NE, Garner CC (2004) Cellular and molecular mechanisms of presynaptic assembly. Nat Rev Neurosci 5: 385-399.

61. Mutch SA, Kensel-Hammes P, Gadd JC, Fujimoto BS, Allen RW, et al. (2011) Protein quantification at the single vesicle level reveals that a subset of synaptic vesicle proteins are trafficked with high precision. J Neurosci 31: 1461-1470.

62. Schikorski T, Stevens CF (1997) Quantitative ultrastructural analysis of hippocampal excitatory synapses. J Neurosci 17: 5858-5867.

63. Price JC, Guan S, Burlingame A, Prusiner SB, Ghaemmaghami S (2010) Analysis of proteome dynamics in the mouse brain. Proc Natl Acad Sci U S A 107: $14508-14513$

64. Marom S (2010) Neural timescales or lack thereof. Prog Neurobiol 90: 16-28.

65. Mammen AL, Huganir RL, O'Brien RJ (1997) Redistribution and stabilization of cell surface glutamate receptors during synapse formation. J Neurosci 17: 7351-7358.

66. Archibald K, Perry MJ, Molnar E, Henley JM (1998) Surface expression and metabolic half-life of AMPA receptors in cultured rat cerebellar granule cells. Neuropharmacology 37: 1345-1353.

67. Kjøller C, Diemer NH (2000) GluR2 protein synthesis and metabolism in rat hippocampus following transient ischemia and ischemic tolerance induction. Neurochem Int 37: 7-15.

68. El-Husseini A, Schnell E, Dakoji S, Sweeney N, Zhou Q, et al. (2002) Synaptic strength regulated by palmitate cycling on PSD-95. Cell 108: 849-863.

69. Steward O, Levy WB (1982) Preferential localization of polyribosomes under the base of dendritic spines in granule cells of the dentate gyrus. J Neurosci 2: 284 291.

70. Ostroff LE, Fiala JC, Allwardt B, Harris KM (2002) Polyribosomes redistribute from dendritic shafts into spines with enlarged synapses during LTP in developing rat hippocampal slices. Neuron 35: 535-545.

71. Kalla S, Stern M, Basu J, Varoqueaux F, Reim K, et al. (2006) Molecular dynamics of a presynaptic active zone protein studied in Munc13-1-enhanced yellow fluorescent protein knock-in mutant mice. J Neurosci 26: 13054-13066.

72. Zeidan A, Ziv NE (2012) Neuroligin-1 loss is associated with reduced tenacity of excitatory synapses. PLoS One 7: e42314.

73. Tsuriel S, Fisher A, Wittenmayer N, Dresbach T, Garner CC, et al. (2009) Exchange and redistribution dynamics of the cytoskeleton of the active zone molecule bassoon. J Neurosci 29: 351-358.

74. Ribrault C, Reingruber J, Petkovic M, Galli T, Ziv NE, et al. (2011) Syntaxin 1A lateral diffusion reveals transient and local SNARE interactions. J Neurosci 31: $17590-17602$

75. Krueger SR, Kolar A, Fitzsimonds RM (2003) The presynaptic release apparatus is functional in the absence of dendritic contact and highly mobile within isolated axons. Neuron 40: 945-957.

76. Dobie FA, Craig AM (2011) Inhibitory synapse dynamics: Coordinated presynaptic and postsynaptic mobility and the major contribution of recycled vesicles to new synapse formation. J Neurosci 31: 10481-10493.

77. Mondin M, Labrousse V, Hosy E, Heine M, Tessier B, et al. (2011) Neurexinneuroligin adhesions capture surface-diffusing AMPA receptors through PSD-95 scaffolds. J Neurosci 31: 13500-11355.

78. Boisvert FM, Ahmad Y, Gierlinski M, Charriere F, Lamont D, et al. (2012) A quantitative spatial proteomics analysis of proteome turnover in human cells. Mol Cell Proteomics 11: M111.011429.

79. Spellman DS, Deinhardt K, Darie CG, Chao MV, Neubert TA (2008) Stable isotopic labeling by amino acids in cultured primary neurons: Application to brain-derived neurotrophic factor-dependent phosphotyrosine-associated signaling. Mol Cell Proteomics 7: 1067-1076.

80. Zhang G, Neubert TA, Jordan BA (2012) RNA binding proteins accumulate at the postsynaptic density with synaptic activity. J Neurosci 32: 599-609.

81. Butko MT, Yang J, Geng Y, Kim HJ, Jeon NL, et al. (2012) Fluorescent and photo-oxidizing TimeSTAMP tags track protein fates in light and electron microscopy. Nat Neurosci. 15: 1742-1751.

82. Blichenberg A, Schwanke B, Rehbein M, Garner CC, Richter D, et al. (1999) Identification of a cis-acting dendritic targeting element in MAP2 mRNAs. J Neurosci 19: 8818-8829.

83. Brewer GJ, Price PJ (1996) Viable cultured neurons in ambient carbon dioxide and hibernation storage for a month. Neuroreport 7: 1509-1512.

84. Link AJ, Vink MK, Tirrell DA (2007) Synthesis of the functionalizable methionine surrogate azidohomoalanine using boc-homoserine as precursor. Nat Protoc 2: 1884-1887.

85. Mudunuri U, Che A, Yi M, Stephens RM (2009) bioDBnet: The biological database network. Bioinformatics 25: 555-556. 